\title{
A Bayesian BWM and VIKOR-based model for assessing hospital preparedness in the face of disasters
}

\author{
Halit Serdar Saner ${ }^{1} \cdot$ Melih Yucesan $^{2} \cdot$ Muhammet Gul $^{2}$
}

Received: 18 June 2021 / Accepted: 8 November 2021 / Published online: 16 November 2021 (c) The Author(s), under exclusive licence to Springer Nature B.V. 2021

\begin{abstract}
Hospitals are the first point of contact for people in the face of disasters that interfere with the daily functioning of life and endanger health and social life. All preparations should be made considering the worst possible conditions and the provided service should continue without interruption. In this study, a multi-criteria decision-making model was developed to evaluate disaster preparedness of hospitals. This decision model includes Bayesian best-worst method (BBWM), the VlseKriterijumska Optimizacija I Kompromisno Resenje (VIKOR) and technique for order preference by similarity to ideal solution (TOPSIS) methods. With the proposed decision model, six main criteria and 34 sub-criteria related to disaster preparedness of hospitals were considered. The criteria and sub-criteria evaluated in pairwise comparison manner by the experts were weighted with BBWM. These weight values and the data obtained from the six Turkish hospitals were combined to provide inputs for VIKOR and TOPSIS. In addition, a comparative study and sensitivity analysis were carried out using weight vectors obtained by different tools. BBWM application results show that the "Personnel" criterion was determined as the most important criterion with an importance value of $26 \%$. This criterion is followed by "Equipment" with $25 \%$, "Transportation" with 14\%, "Hospital building" and "Communication" with $12 \%$, and "Flexibility" with $11 \%$. Hospital-2 was determined as the most prepared hospital for disasters as a result of VIKOR application. The VIKOR Q value of this hospital was obtained as 0.000 . According to the results of the comparative study, Hospital-2 was determined as the most disaster-ready hospital in all six different scenarios. This hospital is followed by Hospital-4 $(\mathrm{Q}=0.5661)$ and Hospital-5 $(\mathrm{Q}=0.7464)$. The remaining rankings were Hospital-6, Hospital-3 and Hospital-1. The solidity of the results was checked with TOPSIS. Based on TOPSIS application results, Hospital-2 was again found the most-ready hospital. The usage of BBWM in this study enabled the expert group's views to be combined without loss of information and to determine the criteria and sub-criteria weights with less pairwise comparisons in a probabilistic perspective. Via the "Credal ranking", which is the contribution of BBWM to the literature, the interpretation of the hierarchy between each criterion has been performed more precisely.
\end{abstract}

Muhammet Gul

muhammetgul@munzur.edu.tr

Extended author information available on the last page of the article 
Keywords Hospital disaster preparedness - Bayesian best-worst method · VIKOR · TOPSIS $\cdot$ Credal ranking

\section{Introduction}

Hospitals are places that people may need at any time throughout their lives. They serve people for daily illnesses, accidents or chronic diseases and operate within a certain system. There is an ongoing cycle in all respects, from the number of employees to the availability of empty beds, from food and water supply to the parking layout. People receive health services from hospitals depending on their location and the area of health they serve. Daily working plans, the quantity of staff per shift and working hours are adjusted according to these situations. In extreme conditions where this ongoing order can be disrupted, hospital emergence services may differ depending on the community's needs. Disasters are events that can cause loss of life or property for people and affect society negatively by disrupting social life and human activities (WHO 2018). In disaster conditions, uncertainty can be experienced both in human health and physically. With the chaotic environment that may occur and panic over people, the possibility of providing a regular service can gradually decrease. The most devastating disasters are earthquakes, floods, storms, landslides, volcanic eruptions, tsunamis, terrorist attacks, chemical explosions, forest fires, building collapse, industrial accidents, major traffic accidents, wars (Yi et al. 2010). These disasters affect an average of 200 million people per year and cause approximately 65,000 to die.

Governments want to ensure that health systems are serviceable and capable in such disruptive situations. Hospitals have a great responsibility in this regard. All precautions should be taken from its construction to its operation period, and a safe environment should be prepared. According to the World Health Organization (WHO), hospitals must first protect three areas: protection of life, investment, and operational protection (WHO 2005). The opportunities offered by the developing technology, the experiences gained after the previous disasters, and the people with increased awareness can help hospitals prepare for the next disaster. With the precautions to be taken, it is possible to prevent the destruction. Thus, the experience of panic is prevented and people can act more systematically. Turkey is a country experienced many natural disasters due to its geographical location. When the data in the Belgium-based Emergency Situations Database (EM-DAT, 2021) were examined, a total of 183 disaster events occurred between 2000 and 2021 (Fig. 1). In 2004, the highest number of disasters experienced with 21 was reached, followed by 2003 with 16 events. The number of disasters experienced in 2013 was only three. Major traffic accidents take the first place among these 183 disasters. Transportation accidents account for nearly half $(45 \%)$ of total disasters, with 83 . It is followed by earthquakes with 27 events (15\%) and floods with 26 events (14\%). As a result of these disasters, 4226 people lost their lives in 21 years (Fig. 2). With two earthquakes in Van and resulted in 644 casualties, 2011 was the year with the highest number of deaths, with 700 in total.

The diversity of disasters experienced in the country in the recent 21 years shows that all kinds of problems can be experienced at any time. It is possible to avoid the chaos that occurs after a disaster by taking individual and social measures. With the measures taken by the hospitals, it is possible to save human lives. This study is aimed at evaluating the preparedness level of Turkish hospitals against disaster conditions. 


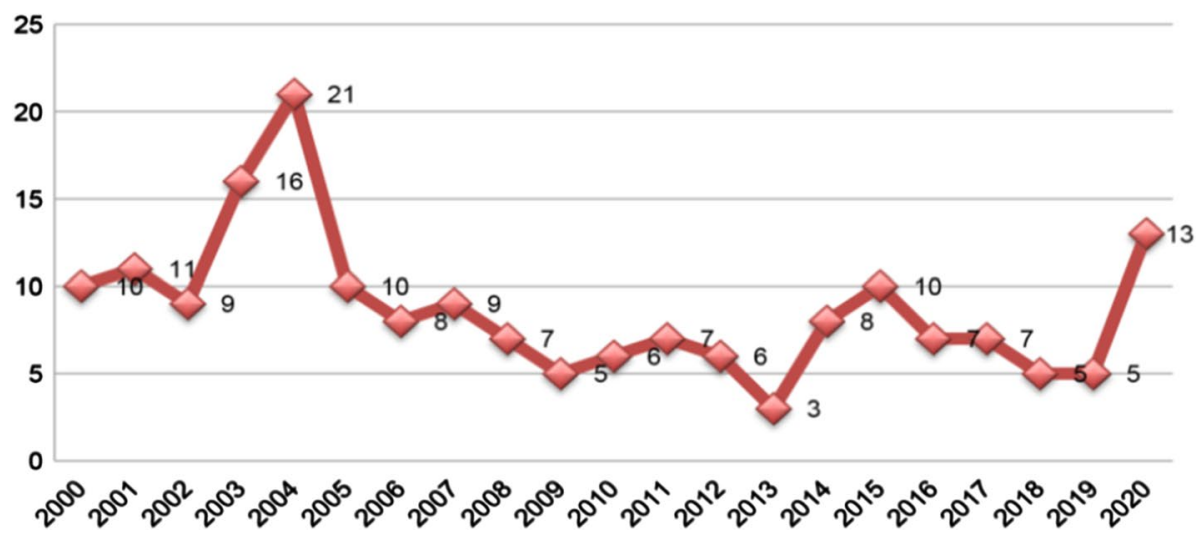

Fig. 1 The number of disaster events in the years 2000-2020

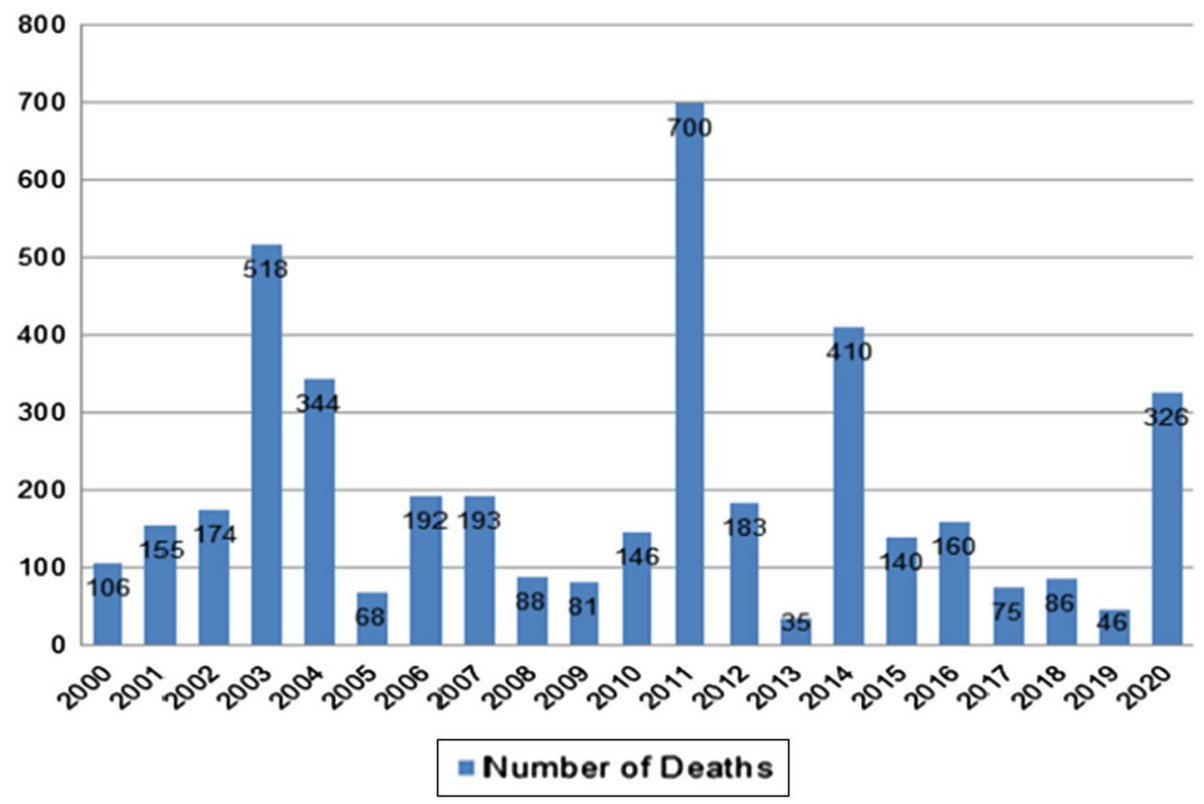

Fig. 2 The number of casualties in the years 2000-2020

\section{Literature review}

Hospital preparations for disaster situations have been covered many times in the literature, both with MCDM methods and conceptually. Evaluated criteria, classifications, data collection methods made the studies different from each other. 


\subsection{Use of MCDM in hospital disaster preparedness}

Ortiz-Barrios et al. (2020) used a hybrid fuzzy decision-making model consisting of FAHP, FDEMATEL and TOPSIS to determine the disaster preparedness level of four hospitals selected from Turkey. Via FAHP, the weights of six criteria regarding readiness were calculated, and FDEMATEL was applied to reveal the interdependence between criteria and sub-criteria. Finally, the ranking of hospitals was obtained via TOPSIS. They stated that the number of hospitals studied could be further increased, and thus the results could be reinforced. They also suggest that those who have a say in the country's management should consider these results during the disaster planning phase. Hosseini et al. (2019) evaluated the preparedness of eight hospitals for disaster situations selected from the Ahvaz region with four main 29 sub-criteria using the TOPSIS technique. Results show that the selected hospitals were not prepared for disasters at the desired level. Marzaleh et al. (2019) conducted a study using the Delphi technique to determine the disaster preparedness of emergency services in Iran regarding the risk of nuclear terrorism and radiation. The weights of 31 preparedness factors determined by 32 experts were compared, and it was determined that the level of preparedness of the personnel was of the highest importance. Ortiz-Barrios et al. (2017) aimed to help hospitals better prepare for major disasters and emergencies. A hybrid model is proposed using AHP, DEMATEL and TOPSIS. As a result, their proposed method effectively improves conciliatory solution methods, facilitates evaluating how well the health system performs and is considered a guide for evaluating emergency services preparedness for disaster situations. Table 1 shows the list and details of the studies in the literature that deal with the disaster preparedness of hospitals.

\subsection{Overview of previous studies}

Gul and Guneri (2015) combined the data from some official reports and one-on-one interviews with the opinions of experts who had experienced earthquakes in Istanbul before to assess the earthquake preparedness of the emergency services in Istanbul. The interviews were analyzed in terms of some critical statements about the earthquake. Important problems encountered during the earthquake in terms of hospital care were identified. Top et al. (2010) examine the plans made by 251 public, university and private hospitals in Turkey with 100 or more beds for possible disaster preparedness. This study revealed that 233 hospitals $(92.8 \%)$ prepare disaster plans, $63.5 \%$ of public hospitals, $80 \%$ of private hospitals and $31.8 \%$ of university hospitals conduct annual practice. Tabatabaei and Abbasi (2016) conducted a cross-sectional study in some Iranian hospitals to assess disaster risks based on the hospital safety index. They determined three main and 145 sub-criteria for the evaluation of disaster preparedness processes with two different questionnaires. Naser et al. (2018) evaluated the disaster preparedness status of 5 public and 5 private hospitals in South Yemen. They determined that the level of preparation of the hospitals was insufficient. Samsuddin et al. (2018) investigated the resilience of hospitals in Malaysia during disasters by applying a cross-sectional questionnaire among staff. They consider 243 readiness qualities and 23 resilience indicators. Human resources, training and immediate reaction skills were determined as the most critical features. Shabanikiya et al. (2019) conducted a study using the Delphi method to keep the capacity increase under control during disasters. They evaluated 13 sub-criteria under 5 main headings to evaluate the preparedness of hospitals for capacity increase in disasters and to plan hospitals' response 


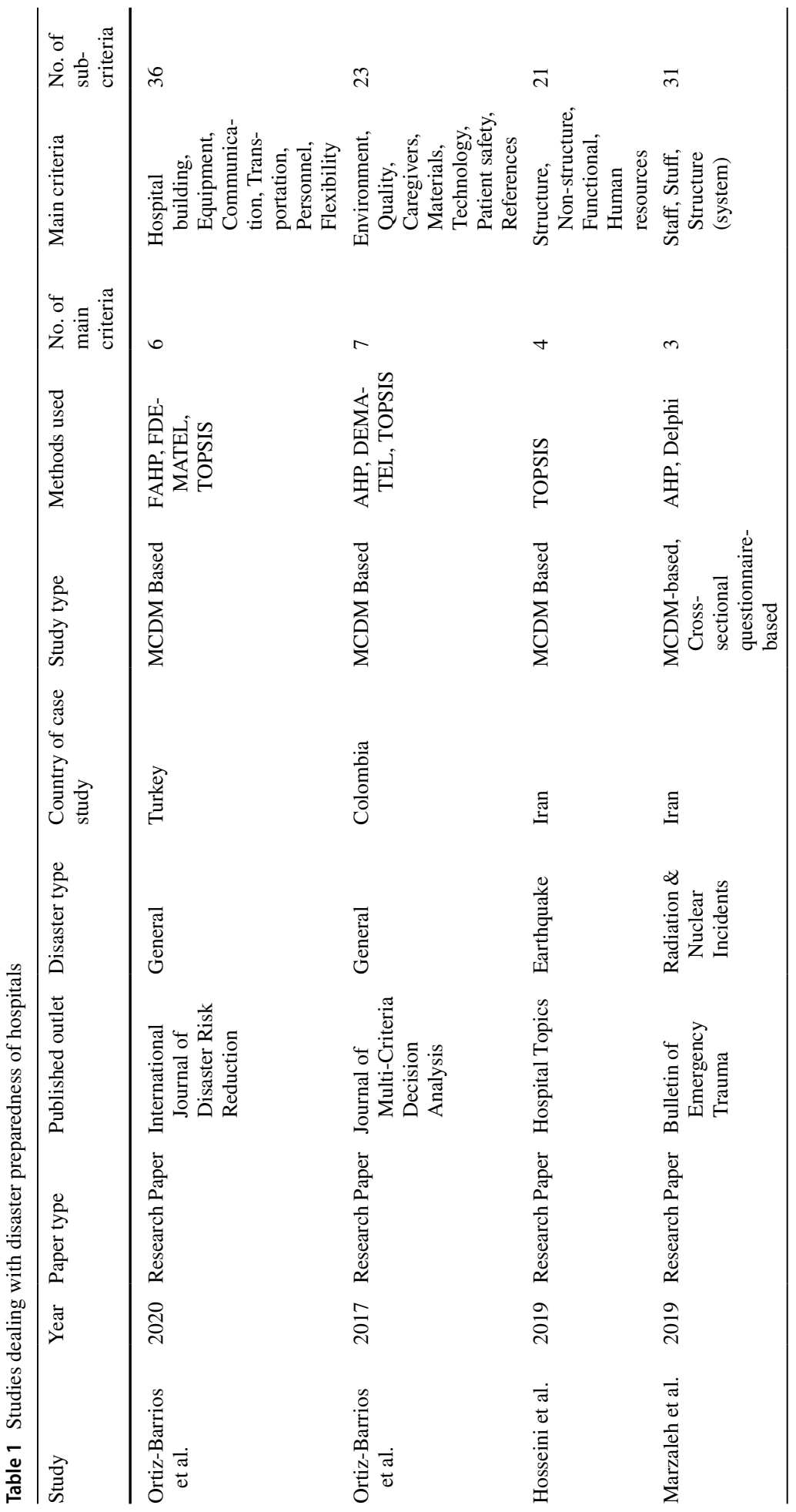




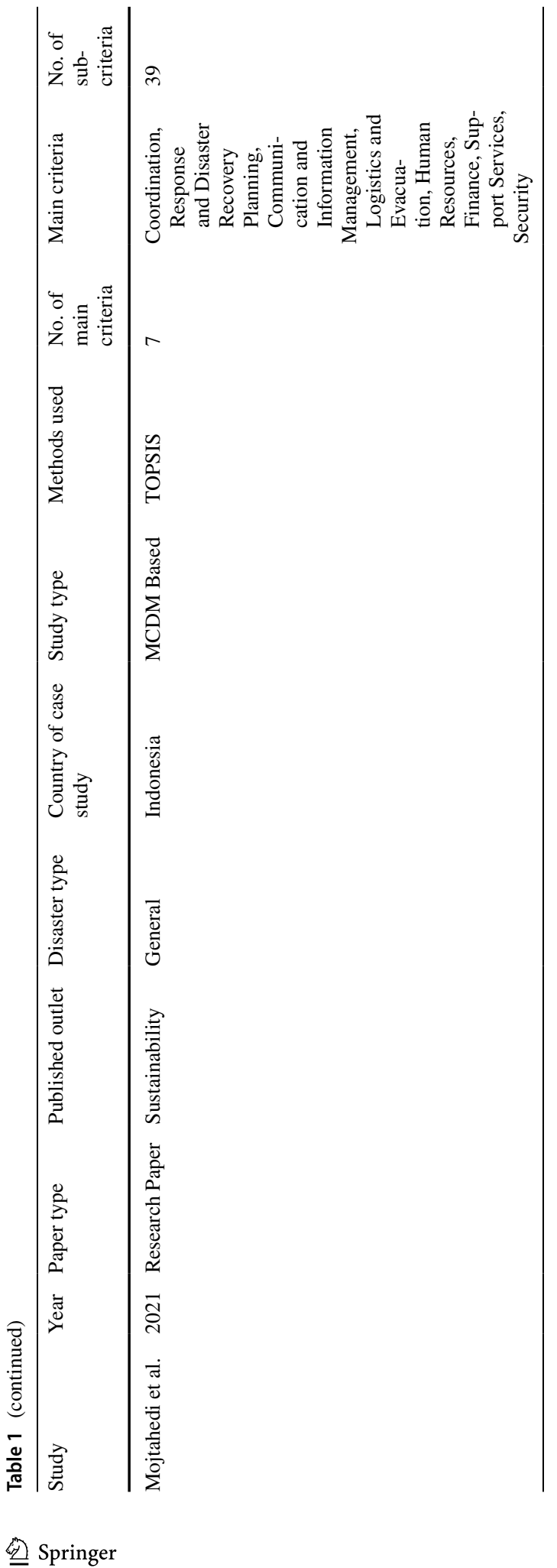


to disasters. Rezaei and Mohebbi-Dehnavi (2019) conducted a study by collecting data with a checklist containing 137 questions. They focus on ten main criteria in ten hospitals they selected in Iran in 2017. Readiness levels of hospitals were determined to be moderate to good. Saeid et al. (2019) prepare a questionnaire for 15 hospitals in Ardabil, Iran. The questionnaire consists of two parts. In the first part, demographic information was obtained, and in the second part, the evaluation of the preparation stages was requested. Insufficient level of preparation was determined for triage and human resources. Munasinghe and Matsui (2019) gathered information from doctors and nurses with a questionnaire in Sri Lanka in 2019, frequently faced with disasters. They determined that there was not enough preparedness for disasters. Adini et al. (2006) determined that the number of exercises should be increased. The capacity should be expanded as a result of the evaluation made in Israel, where chemical injuries are common. Al Thobaity et al. (2019) evaluated eight state hospitals from two cities in Saudi Arabia. Five main criteria, which are considered the most important in the disaster preparedness process, were determined. Mulyasari et al. (2013) determined six main criteria with 21 sub-criteria via survey in the hospitals of eight cities in Japan, where large earthquakes are common. After major disasters such as tsunami and earthquakes, zoning preparations were carried out successfully. Olivieri et al. (2017) determined seven main and 30 sub-criteria as important against CBRN disasters with the information obtained from 10 different participants and Delphi technique analysis. Zhong et al. (2014) determined four main criteria that hospitals should pay attention to within the scope of disaster preparedness. The study was conducted in three hospitals in the Shandong province of China and showed the insufficient capacity of hospitals. Moheimani et al. (2021a) examined the preparedness of 25 hospitals against the COVID19 pandemic in Tehran. The data were collected with 3 doctors who are experts in their fields and who have knowledge of the hospitals' conditions. The data were processed by Rosetta software. It was determined that there was a need for medical equipment and drug resources. Also, a second study by Moheimani et al. (2021b) focused on assessing the agility of hospitals in disaster management. They developed an interval type-2 fuzzy Flowsort inference system-based model and assessed 30 hospitals' agility in disasters. Gul and Yucesan (2021) assessed hospital preparedness against COVID-19 pandemic. They proposed an interval-valued fuzzy MCDM method to rank hospitals according to their preparedness against COVID-19 and evaluated three hospitals according to 10 readiness components for COVID-19. Results of their study showed that the highest components include surveillance, communication, logistics and supply chain management, and laboratory services. Nekoie-Moghadam et al. (2016), Alruwaili et al. (2019) and Verheul and Dückers (2020) have contributed to the literature by preparing state-of-the-art review articles by retrieving 15,19 and 40 articles, respectively.

\subsection{Potential gaps and our contributions}

In this study, the disaster preparedness of hospitals was evaluated with a decision model including BBWM, VIKOR and TOPSIS. The contributions and differences of this model to the literature can be summarized as follows:

- The BBWM method was used for the first time in this field. Unlike the MCDM methods used in previous studies within the scope of disaster management, there is no loss of information in combining expert opinions thanks to BBWM. From a probabilistic view, criterion and sub-criteria weights are determined with less pairwise comparisons. 
- In interpreting the hierarchical ranking between the criterion weights, a more precise output was obtained via "credal ranking," which BBWM brought to the literature. It is easier and more understandable to evaluate the difference between the weights of the criteria.

- In addition to the proposed BBWM-VIKOR based method, the consistency of the result reached with alternative solutions was checked. Pearson correlation analysis was used to analyze the relationship between the results produced by alternative approaches that tested the applicability and robustness of the method with a detailed comparison study.

\section{Methodology}

\subsection{BBWM method}

Although the original BMW can make different evaluations using two vectors for each decision-maker, it does not allow the assessment of different decision-makers to be aggregated (Mohammadi and Rezai 2020a). To aggregate decision-makers' evaluations, Hafezalkotob and Hafezalkotob (2017) proposed democratic and autocratic decision-making styles. Mou et al. (2016) used fuzzy multiplicative weighted geometric aggregation. BBWM was proposed by Mohammadi and Rezai (2020a) to aggregate decision-makers' evaluations in the probabilistic environment, and it is an extension of the BWM proposed by Rezai (2015).

BBWM consists of three steps. In the first step, the criteria were determined. In the second step, a survey was prepared in accordance with the original BWM evaluation. In the third step, the problem was made applicable to BBWM with a probabilistic perspective after evaluating according to the original BWM proposed by Rezaei (2015). The implementation steps are presented in the following with an acceptable level of detail (Hsu et al. 2021; Mohammadi and Rezaei, 2020b) and presented in Fig. 3.

Step 1: Determining the criteria to be evaluated. The criteria and the scope of these criteria are determined.

Step 2: Creating a survey in a form suitable for BWM assessment. A form was prepared for decision-makers to determine the best and worst criteria, and the comparison carried out best and worst criteria with other criteria.

Step 3: Calculation of criterion weights based on expert evaluations. In Steps 3.1-3.3, the original BWM procedure recommended by Rezaei (2015) was applied.

Step 3.1: Expert k first selects the best $c_{B}^{k}$ and the worst $c_{W}^{k}$ criteria from the list. In this step, decision-makers choose the best and worst criterion from the list of criteria. No pairwise comparison is made at this stage.

Step 3.2: Decision-makers are evaluated by paired comparison with the best criteria $c_{B}^{k}$ and other criteria. Each decision-maker compares the previously determined best/most important criterion with the other criterion in this step. The numbers between 1 and 9 are used when comparing. Criteria that perform close to the most important criterion have relatively low values, while comparing the best criterion with the worst criterion takes the greatest value. At this stage, the Best-to-Others vector $\left(A_{B}^{k}\right)$ is obtained.

$$
A_{B}^{k}=\left(a_{B 1}^{k}, a_{B 2}^{k}, \ldots, a_{B n}^{k}\right), k=1,2, \ldots, K
$$

where $a_{B j}^{k}$ represents the preference of the best criteria $\left(c_{B}^{k}\right)$ over. $c_{j} \in C$ for expert k.

Step 3.3: The decision-maker compares the worst criterion with the other criteria previously determined. The comparison procedure is similar to Step 3.2. 


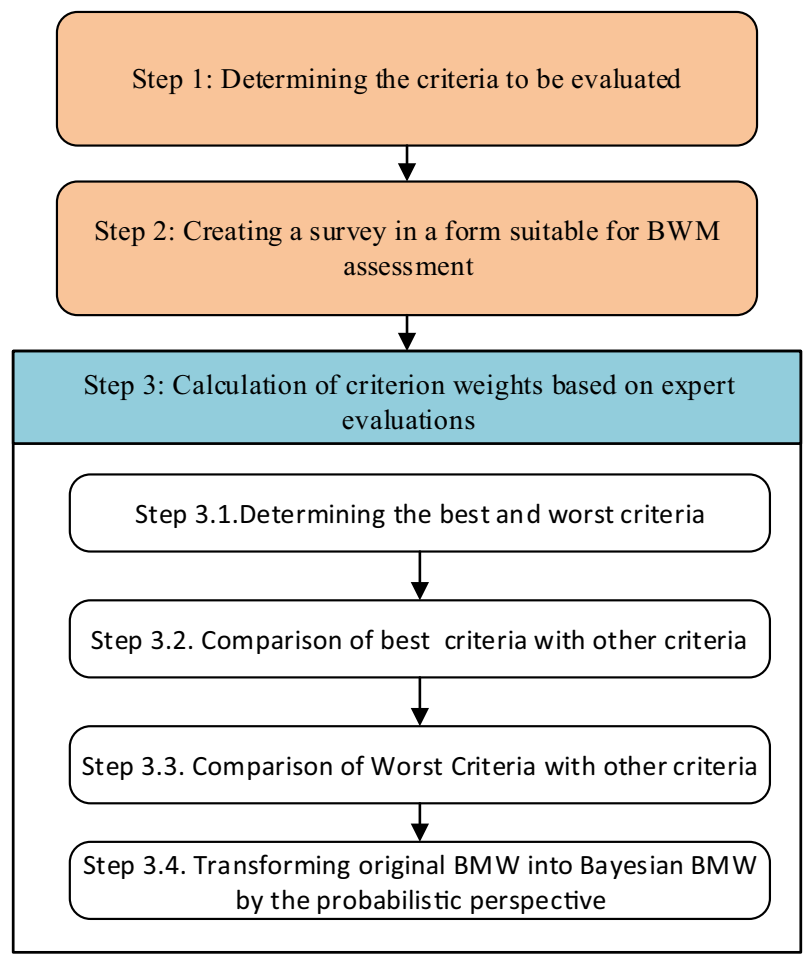

Fig. 3 Implementation steps in BBWM

$$
A_{W}^{k}=\left(a_{1 W}^{k}, a_{2 W}^{k}, \ldots, a_{n W}^{k}\right)^{T}
$$

where $a_{j W}^{k}$ represents the preference of the best criteria $c_{W}^{k}$ over. $c_{j} \in C$ for expert k.

Step 3.4: Transforming BMW into Bayesian BMW by the probabilistic perspective. When viewed from the probability perfective, the criteria are random events, and the weights of these criteria can be evaluated as probabilities of occurrence. In probability theory and MCDM problems $w_{j} \geq 0$ and $\sum_{j=1}^{n} w_{j}=1$. Therefore, it makes sense to use probabilistic modeling for decision-making models. In probability models, all inputs and outputs should be modeled as probability distributions. First of all, the criteria are evaluated, and $A_{B}$ best and $A_{w}$ worst criteria are determined. The multinomial distribution is modeled. For this modeling, all elements must be integers (Forbes et al. 2001). The probability mass function related to the worst criterion $A_{w}$ is:

$$
P\left(A_{w} \mid w\right)=\frac{\left(\sum_{j=1}^{n} a_{j W}\right) !}{\prod_{j=1}^{n} a_{j W} !} \prod_{j=1}^{n} w_{j}^{a_{j W}}
$$

where $\mathrm{w}$ represents the probability distribution. In the multinomial distribution, $A_{w}$ contains the number of times each event occurs. The probability of the $\mathrm{J}$ event is closely related to the total number of trials. 


$$
w_{j} \propto \frac{a_{j W}}{\sum_{i=1}^{n} a_{i W}}, \forall j=1, \ldots, n .
$$

Similarly,

$$
w_{W} \propto \frac{a_{j W}}{\sum_{i=1}^{n} a_{i W}}=\frac{1}{\sum_{i=1}^{n} a_{i W}}
$$

Using Eqs. (2) and (3), one obtains $\frac{w_{j}}{w_{w}} \propto a_{j W} \forall j=1, \ldots, n$.

The $A_{B}$ can be calculated using the multinomial distribution. But $A_{B}$ and $A_{w}$ are different from each other. While the $A_{B}$ compares the most important criterion with other criteria, $A_{w}$ includes evaluating the worst criterion with other criteria. Thus $A_{B}$ gives the reverse of weight.

$$
A_{B} \sim \text { multinominal }(1 / w)
$$

w represents the probability distribution. / is the division operator. Similar to the Worst criterion

$$
\frac{w_{B}}{w_{j}} \propto a_{B j} \forall j=1, \ldots, n
$$

It has been shown that conventional BWM inputs can be modeled as a multinomial distribution. Thus, weighting for MCDM problems has turned into a problem of determining the probability distribution. For this reason, statistical inference techniques can be used to find the weights. Obtaining the aggregated weights $w^{*}=\left(w_{1}^{*}, w_{2}^{*}, \ldots, w_{n}^{*}\right)$ and the weight for each decision-maker $w^{k}, k=1, \ldots, K$ based on the following probabilistic model:

$$
\begin{gathered}
\left(A_{B}^{k} \mid w^{k}\right) \sim \text { multinominal }(1 / w), \quad \forall k=1, \ldots, K \\
\left(A_{W}^{k} \mid w^{k}\right) \sim \operatorname{multinominal}\left(w^{k}\right), \quad \forall k=1, \ldots, K \\
\left(w^{k} \mid w^{*}\right) \sim \operatorname{Dir}\left(\gamma x w^{*}\right), \quad \forall k=1, \ldots, K \\
\gamma \sim \operatorname{gamma}(0.1,0.1), \\
w^{*} \sim \operatorname{Dir}(1)
\end{gathered}
$$

where multinomial is the multinomial distribution, Dir is the Dirichlet distribution, and gamma $(0.1,0.1)$ is the gamma distribution with shape parameters of 0.1. JAGS, one of the Monte Carlo methods, is used to solve this model. The probability distributions of $\mathrm{W}$ are criteria weights based on decision-makers' evaluations. Additionally, the credal ordering is calculated by the same procedure as Mohammadi and Rezaei (2020a).

\subsection{VIKOR method}

The VIKOR method has been developed for multi-criteria optimization of complex systems by Opricovic and Tzeng (2004). It is a very effective method to solve multiple attribute 
decision-making (MADM) problems. Its use has become widespread in recent years, especially in the economy, business, and management (Gao et al. 2020; Gul et al. 2016). It supports decision-making mechanisms by identifying cost and benefit criteria and a ranking procedure under these conditions (Rafieyan et al. 2020; Dong et al. 2017). It allows sorting and selecting among conflicting criteria by using pre-determined criteria weights. It further provides a ranking index using a measure of closeness to the ideal solution (Opricovic 1998; Opricovic and Tzeng, 2004; Jahan et al. 2011). Solution steps of the VIKOR method are as follows (Opricovic 1998; Opricovic and Tzeng, 2004):

Step 1: Determine the best $f_{i}^{*}$ and the worst $f_{i}^{-}$values of all criterion functions, $i=1,2, \ldots, m$. If the $i$ th function represents a benefit or cost, then:

$$
\begin{aligned}
& f_{i}^{*}=\max _{j} f_{i j}, f_{i}^{-}=\min _{j} f_{i j}, \text { if the } i \text { th function represents a benefit, } \\
& f_{i}^{*}=\min _{j} f_{i j}, f_{i}^{-}=\max _{j}, \text { if the } i \text { th function represents a cost }
\end{aligned}
$$

Step 2: Compute the values $S_{j}$ and $R_{j}$, by the relations

$$
\begin{gathered}
S_{j}=\sum_{i=1}^{n} w_{i}\left(f_{i}^{*}-f_{i j}\right) /\left(f_{i}^{*}-f_{i}^{-}\right) \\
S_{j}=\max \left[w_{i}\left(f_{i}^{*}-f_{i j}\right) /\left(f_{i}^{*}-f_{i}^{-}\right)\right]
\end{gathered}
$$

Step 3: Calculate $Q_{j}$ values $j=1,2, \ldots, n$, according to the $S_{j}$ and $R_{j}$ using Eq. (8).

$$
Q_{j}=v \frac{\left(S_{j}-S^{*}\right)}{\left(S^{-}-S^{*}\right)}+(1-v) \frac{\left(R_{j}-R^{*}\right)}{\left(R^{*}-R^{*}\right)}
$$

where $S^{*}=\min _{j} S_{j}, S^{-}=\max _{j} S_{j}, R^{*}=\min _{j} R_{j}, R^{-}=\max _{j} R_{j}, v \in[0,1]$ is the weight of the decision-making strategy of the "majority of attributes" (or "maximum group utility").

Step 4: Rank the alternatives, sorting by the values $S, R$ and $Q$ in decreasing order.

Step 5: Propose a compromise solution to the alternative $\boldsymbol{A}_{1}$, which is ranked as the best by the measure $\boldsymbol{Q}$ (minimum).

\subsection{Incorporation of BBWM and VIKOR methods in assessing hospital disaster preparedness: the proposed framework}

This study consists of four stages, as seen in Fig. 4. These stages are: preparation, BBWM application, VIKOR application and comparison \& sensitivity analysis. During the preparation phase, the purpose of the study, the criteria set to be used, the performance criteria to be measured, and data collected for the criteria set are determined. Data on these performance measures are obtained from six different hospitals. The second stage is regarding the BBWM application. The expert team makes the evaluations at this stage, and then the aggregated evaluations are processed in the MATLAB. Finally, the criteria weights and sub-criteria weights are determined. In addition, the credal ranking graphs analyzed extra information about the interrelationship between the criteria. The third phase is on the VIKOR implementation. At this stage, the decision matrix is created with the data collected from the hospitals and the weight vector obtained by BBWM. Then, S, R and Q values for each hospital are calculated with the aid of a decision support system developed 


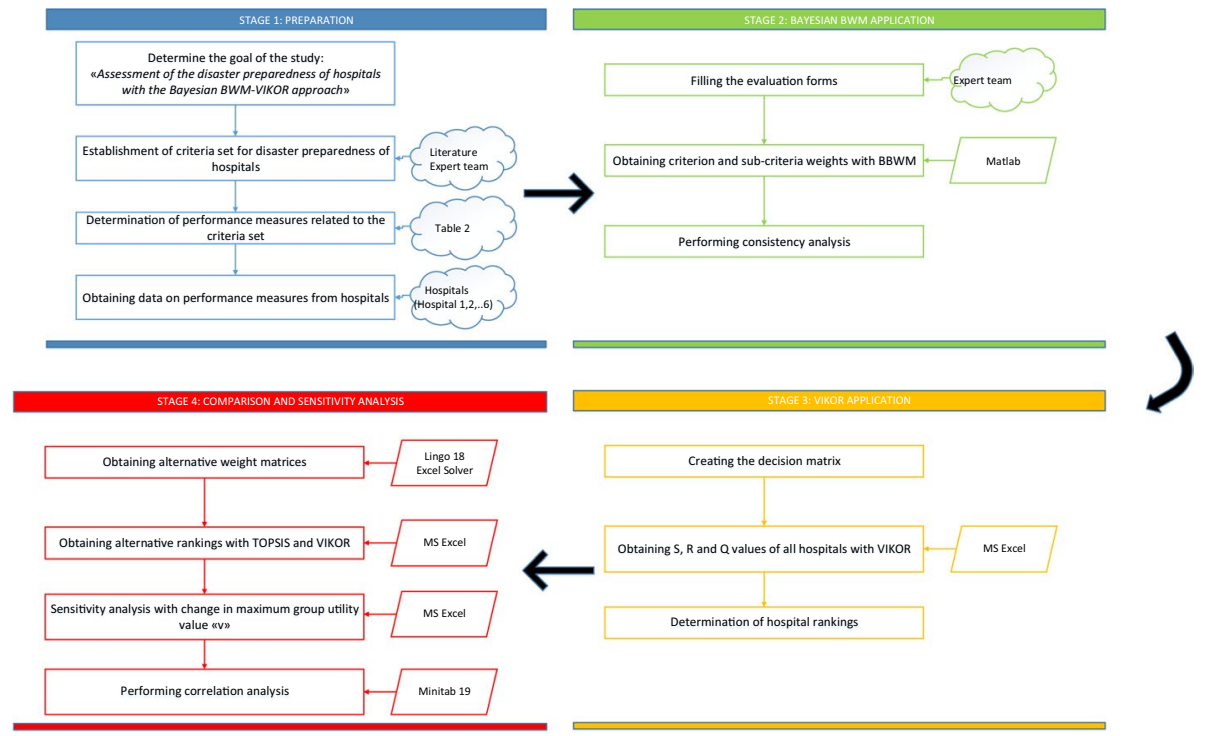

Fig. 4 Flowchart of the proposed approach

with MS Excel. Finally, the hospital rankings are determined. The fourth and final stage is the stage where comparison and sensitivity analyzes are performed. Firstly, criteria and sub-criteria weights are determined using two different commercial software tools (LINGO and Excel Solver). These alternative weight vectors are used in both VIKOR and TOPSIS, resulting in hospital rankings for a total of six different approaches. As a different sensitivity study, the change in the final Q values is determined by changing the maximum group benefit parameter in VIKOR. Finally, a Pearson correlation analysis study is conducted between the final score values obtained from six different approaches, and the relationship between the results produced by the approaches is analyzed.

\section{Case study}

BBWM, VIKOR and TOPSIS methods are presented to test the proposed model's applicability. In this context, firstly, detailed information is given about six main and 34 subcriteria related to disaster preparedness of hospitals (Table 2). Afterward, performance criteria related to these criteria and sub-criteria were determined, and data related to these performance criteria were collected from six different hospitals. The characteristic features of the hospitals are also presented. Five experienced experts evaluated criteria and subcriteria. Initially, Ten experts were contacted, half of whom provided feedback. Since the pairwise comparison of criteria in the BBWM method requires expertise and experience, a limited number of decision-makers have been worked with. The expert group, whose evaluations are consulted, consists of academics who study the subject and decision-makers with field experience. Information such as experience, age and work area of these experts were shared. In the second stage, the disaster preparedness of the hospitals was evaluated with VIKOR and TOPSIS methods. 


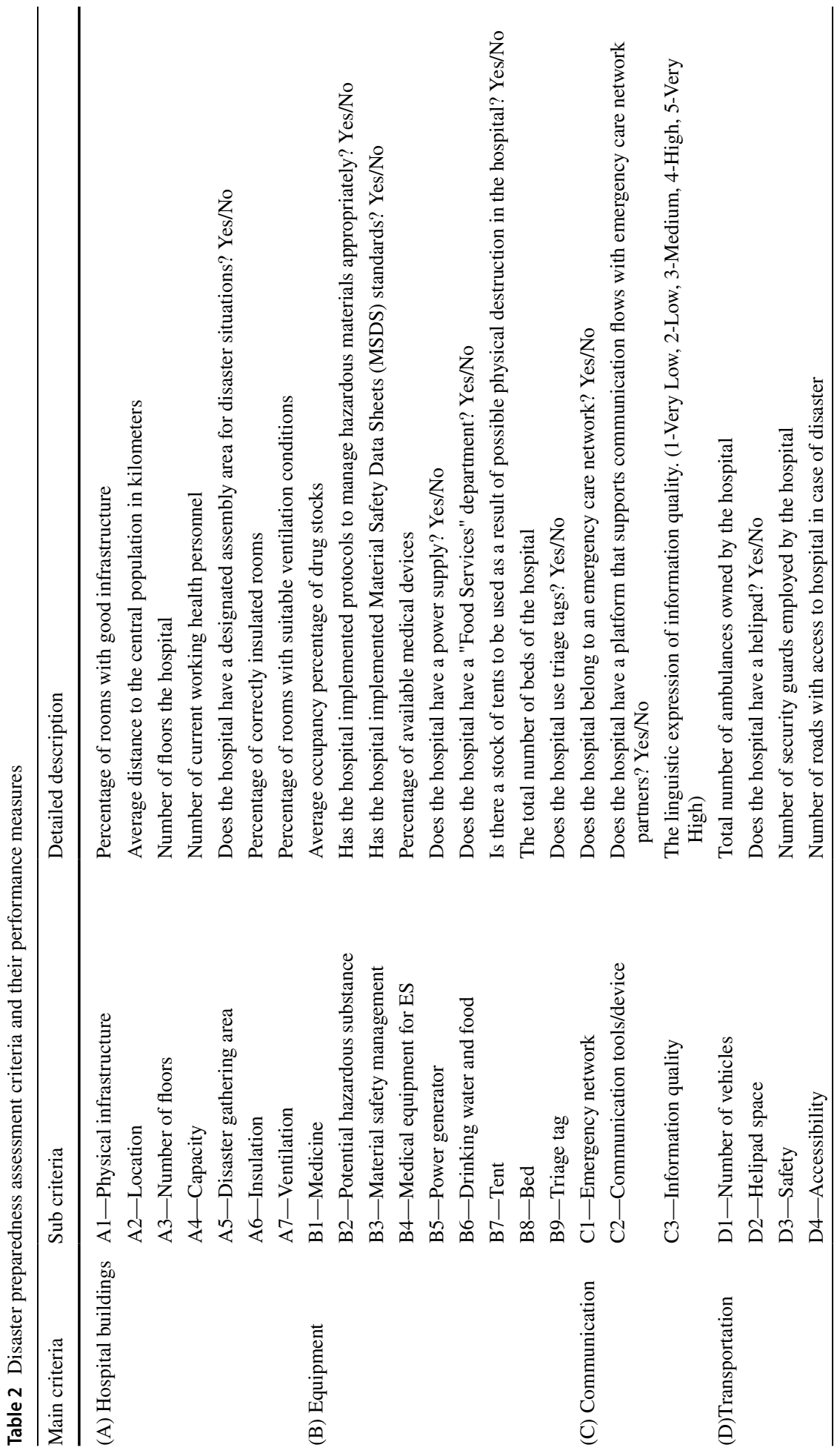









\subsection{Description of hospital disaster readiness criteria hierarchy}

Disaster impact on health facilities, emergency polyclinics (Mulyasari et al. 2013). If the hospitals cannot withstand the disaster, it has negative social consequences on the people's morale. Post-disaster impacts differ depending on various factors, such as the type of disaster, unpreparedness, the capacity of the health system, and risk-related conditions. Huge investments are required in the development of healthcare facilities, such as reconstruction and rehabilitation. Disasters impose direct costs regarding damage to hospital buildings, equipment, replacement facilities and materials, and indirect costs that are often not fully accounted for and can be higher than direct costs. (United Nations 2009). Publishing a series of safe hospital reports and toolkits to help hospitals be better prepared for disasters, WHO defines safe hospitals as "health facilities whose services operate at maximum capacity and within the same infrastructure and are accessible during and immediately after disasters, emergencies or crises (WHO/PWHO, 1996; WHO/PWHO, 2003)." Safe hospitals have three goals:

- Protecting the lives of patients, visitors and hospital staff.

- Protecting the equipment used in the hospital and the investment made in them.

- Maintaining the hospital's performance by continuing its regular operation.

It has been determined that making the facilities safer with the measures taken in this way is much more economical than the reconstruction expenditures after the disasters to be experienced. (WHO 2008). Adini et al. (2006) defined the main components of a high level of preparedness for disasters as planning, infrastructure, knowledge skills and training (Fig. 5).

It is essential for healthcare institutions to design emergency preparedness plans that will keep the number of injured people to a minimum, with the awareness that unforeseen disasters can occur at any time unless they are caused by negligence (Kaji et al. 2007).

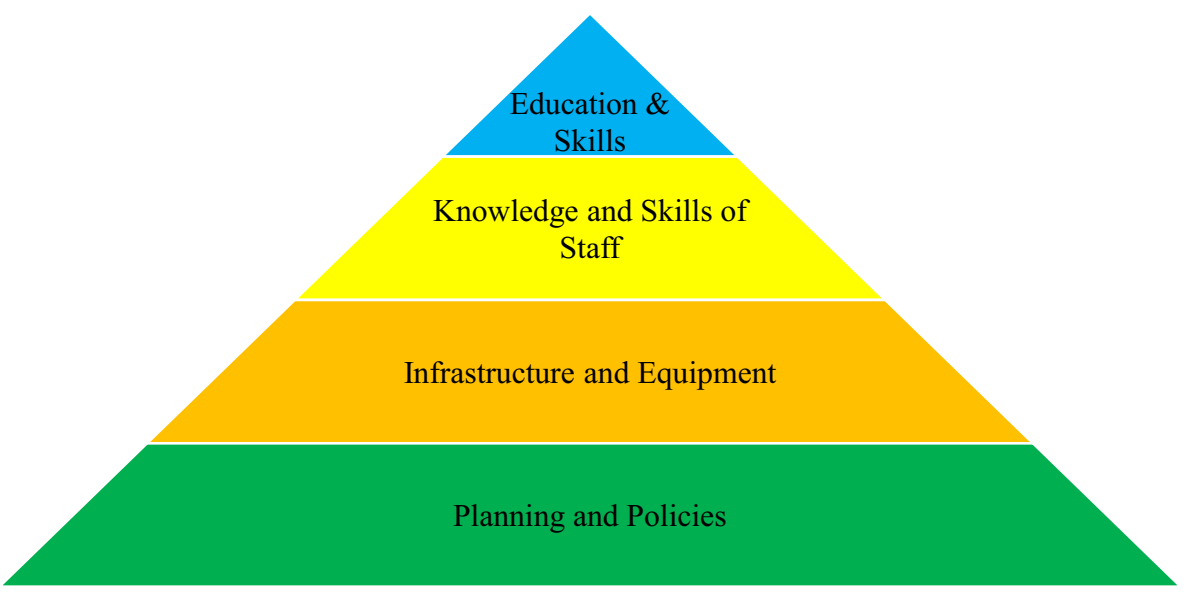

Fig. 5 Components of preparedness for disaster situations (Adini et al. 2006) 


\subsection{Design of questionnaire and decision-making team}

In our study, four academicians who have academic studies in the hospital and a researcher who completed their higher education in this field took part as decisionmakers. These experts, four of whom are in the age range of 35-40 and one between the ages of 40 and 45, continue to contribute to the literature in health and engineering. Expert-1 is an associate professor with 12 years of academic experience, has many studies in hospitals' disaster preparedness, and has a doctorate in this field. As an associate professor with 7 years of academic experience and a doctorate in econometrics, Expert -2 continues to work in the engineering and health sectors. Having worked on demand forecasting in healthcare systems, operations research methods and optimization in manufacturing and healthcare sectors, Expert -3 continues his 10-year academic career as an associate professor. Expert -4 completed his higher education in the field of disaster preparations and works in the IT sector. Having 8 years of private sector experience in quality, process improvement and Six Sigma, Expert -5 has been working as an academic for 12 years.

\subsection{Description of studied hospitals}

Hospital-1 is an integrated hospital serving in a district far from the city center where it is located and where transportation is difficult. Due to the natural disasters experienced in the region, the demand intensity increases frequently. For this reason, the bed capacity has increased compared to the previous years. Hospital-2 is one of the largest city hospitals in the country. It was built in a very large area with state-of-the-art equipment to meet the city's needs and neighboring provinces. Seven different hospitals serve from one center. Apart from these, the 100-bed HSFP (High-Security Forensic Psychiatry) hospital is also in campus. The hospital is relatively far from the densely populated area. We can explain this because the wide area established cannot be found in a central area. Hospital-3 is a hospital specializing in the education and research of cardiovascular diseases in the country's northeast. This hospital has the status of Training and Research Hospital. It serves with 12 departments. It is about $5 \mathrm{~km}$ from the city center. It has the status of Hospital-4 Health research and application Center. The hospital provides service with 40 units. In this respect, it is one of the largest hospitals in the region. Substance Addiction Treatment Center, Genetic Diseases Diagnosis Center, Child Monitoring Center, Infant Intensive Care Unit and Oncology Centers make this hospital different. It is approximately $15 \mathrm{~km}$ from the city center. Hospital-5 is one of the oldest hospitals in the region. The hospital is located in the city center and operates with 21 departments. Hospital-6 specializes in bone diseases. It serves with 7 departments. It differs from other hospitals in the region with and robotic walking unit. It is about three $\mathrm{km}$ from the city center.

\subsection{Implementation of the proposed framework}

In this section, the weights of disaster preparedness criteria of hospitals were determined with BBWM. In this context, the problem has been solved by following the BBWM steps presented in Sect. 3.2. The procedure followed is detailed as follows:

Step 1: Out of 34 sub-criteria, A2 (Location) criterion was determined as cost criterion, while all other sub-criteria were determined as benefit criterion. Because the 
location criterion is a criterion that expresses the average distance of the hospital from the target community, it is desirable to have a low value. A (Hospital Building) criterion consists of seven sub-criteria. In addition, B (Equipment) criterion consists of nine subcriteria, C (Communication) criterion has three, D (Transportation) criterion has four, $\mathrm{E}$ (Personnel) criterion has six, and F (Flexibility) criterion has five sub-criteria.

Step 2: In this step, the best and worst criteria are determined by five experts, and based on this, "best-to-others" and "others-to-worst" evaluation matrices are created. While doing this, a user-friendly decision support system has been developed to collect the decisionmakers' evaluations easily. All evaluations are combined through this decision support system. In the evaluations, a scale of 1-9 expressed in Rezaei (2015) was used. During the evaluation of both criteria and sub-criteria, comparing the criteria/sub-criteria with themselves will be considered equally important. There are a total of five evaluations included in this study. For each evaluation, two tables were filled (Best-to-Others and Others-toWorst). The selection of the best and worst criteria was carried out as in Fig. 6. Pairwise comparisons were made as in Fig. 7. The evaluations obtained from the decision support system are shown in detail in Table 3.

Step 3: The first three sub-steps of this step were carried out with the help of the developed decision support system as mentioned above. In the 4th sub-step, the procedure specified in Mohammadi and Rezai (2020a) was followed. MATLAB codes related to this procedure have been shared by the authors at (URL-1, 2021). The codes have been customized and run for the evaluations presented above. As a result of this run, the local weight values of the criteria and sub-criteria were obtained. In addition, credal rankings were determined, and special graphics related to them were also presented. The main criteria weights obtained with BBWM are presented in Table 4. In Fig. 8, the credal ranking graph of the main criteria is given.

The "E (Personnel)" criterion was determined as the most important criterion with a value of 0.2562 . The conclusion we can draw from this is that no matter how comprehensive and correct the emergency plans in hospitals are, it is possible to implement this plan without any problems if there are sufficient trained personnel. As a result of the evaluation

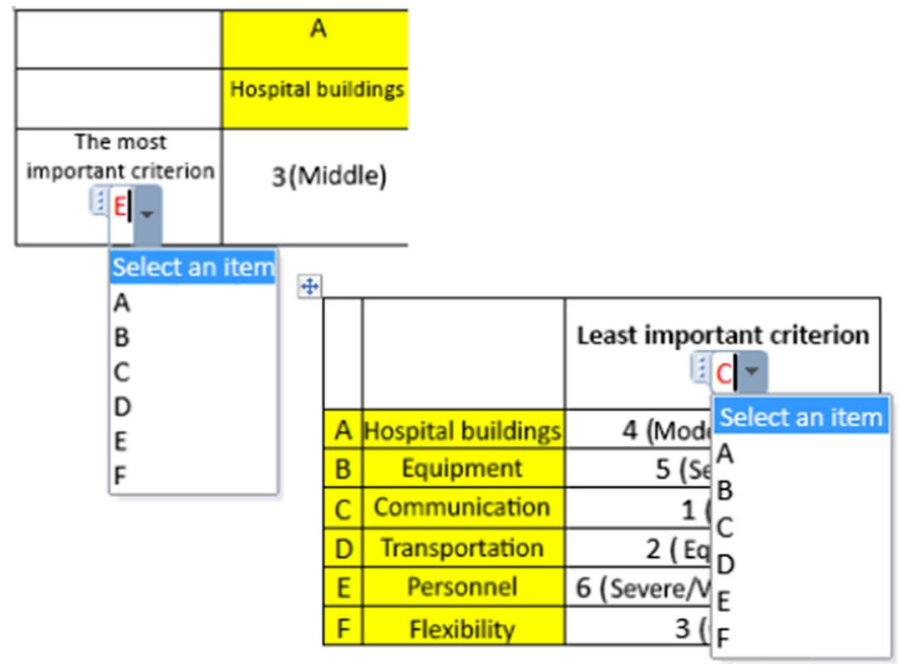

Fig. 6 Selection of best and worst criterion 


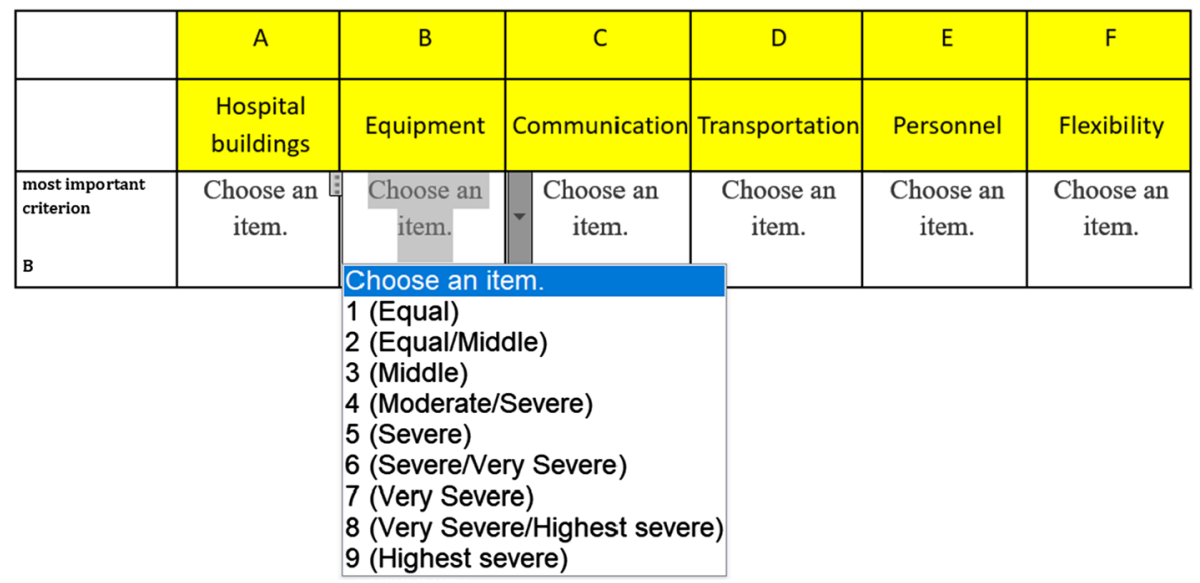

Fig. 7 Pairwise comparisons

of our decision-makers, the second most important criterion with a minimal margin was "B (Equipment)" with a value of 0.25427 . Ready-to-use equipment will be the greatest need of adequate and trained personnel to put what they know into practice. After these two criteria, D (Transportation) came in third place, considering the necessity of hospitals to be applied after the injury and shock experienced during the disaster, to be close to the location. A (Hospital Building) came in fourth place, with its resilience to disasters and the capacity to continue its service in the face of intense patient increase. $\mathrm{C}$ (Communication) criterion is the fifth in importance as it is not considered difficult thanks to the developing technology, and F (Flexibility) has been determined as the least important criterion by our decision-makers. While determining criterion weights with MCDM, criteria with high values are considered more important. However, when ranking, there may be a slight difference between two criteria close to each other in value. This emerges as an important consideration for group decision-makers when calculating weights. The importance of the credal ranking (Mohammadi and Rezai (2020a)), which shows how superior a criterion is to another criterion, emerges at this point. It is necessary to evaluate the values in Fig. 8 in this way. The values written above the arrows in Fig. 8 show that criterion $\mathrm{A}$ is more important than criterion $\mathrm{B}$ in $\left(A \rightarrow^{D} B\right) \mathrm{D}$ reliability. The value of $\mathrm{D}$ here is a probability value and ranges from 0 to 1 . For example, the $E \rightarrow^{1} F$ in Fig. 8 shows that the E criterion is definitely more important than the F criterion. Because the reliability value here is 1 . In the same graph, it is seen that this criterion is not superior to other criteria since there is no arrow going from the $\mathrm{F}$ criterion to the others. The $E \rightarrow^{0,51} B$ expression can be interpreted as follows: Although the weight value of criterion $\mathrm{E}$ is greater than the weight value of criterion $\mathrm{B}$, a reliability value of 0.51 indicates that the absolute superiority of both criteria to each other is a weak possibility. Weight rankings and credal rank representations of subcriteria obtained by BBWM are as in Table 5 and Fig. 9.

In order to determine the disaster preparedness level of the hospitals with the VIKOR MCDM method, a VIKOR score was obtained by using the criteria weights determined by BBWM and the data obtained from six different hospitals (performance criteria for each criterion). The $\mathrm{S}, \mathrm{R}$ and $\mathrm{Q}$ values specific to the VIKOR method were calculated, and the $v$ value, which expresses the maximum group utility coefficient, was taken as 0.5 . For the best and worst performance values calculated in the second stage of VIKOR, the A2 


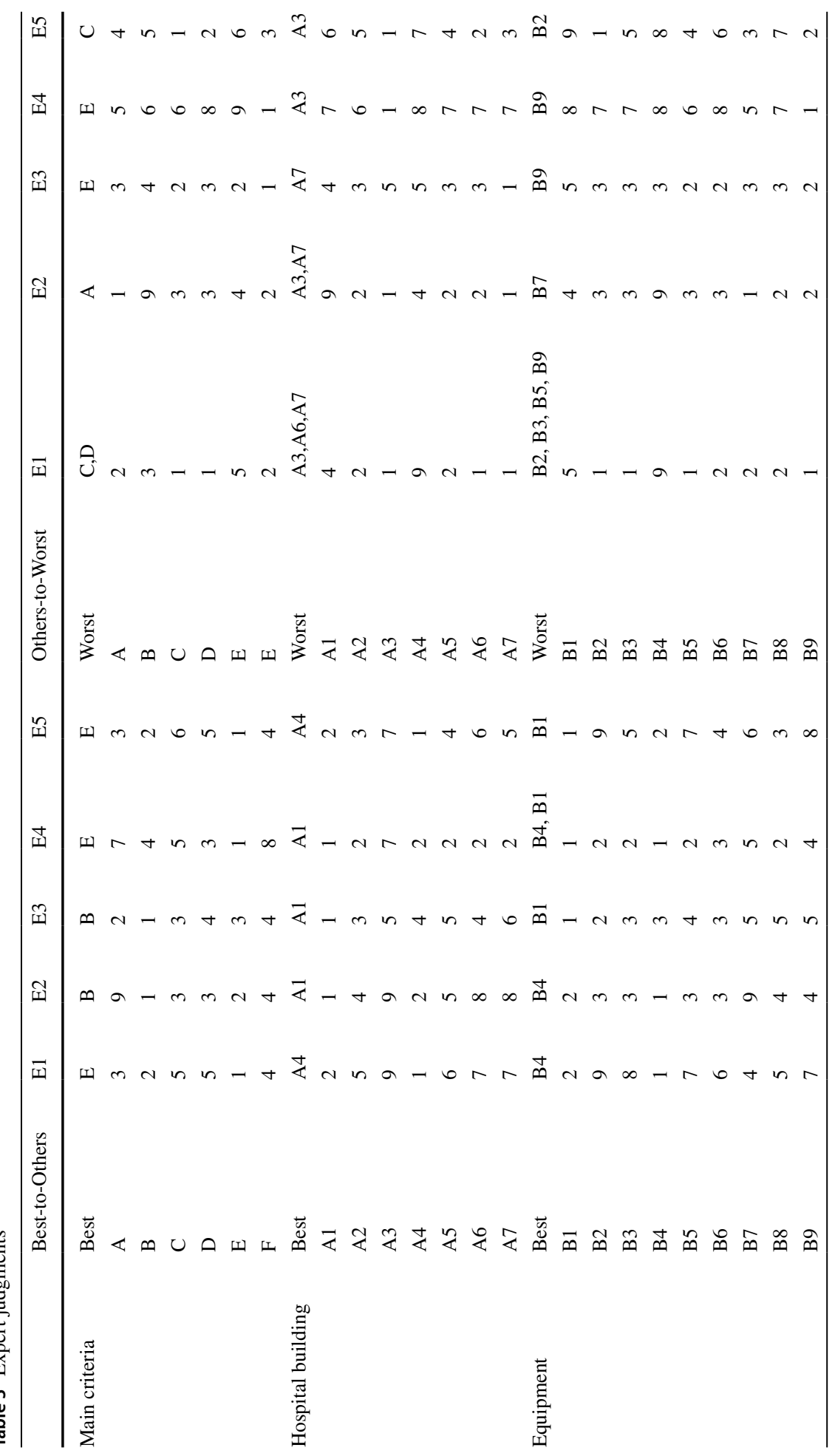




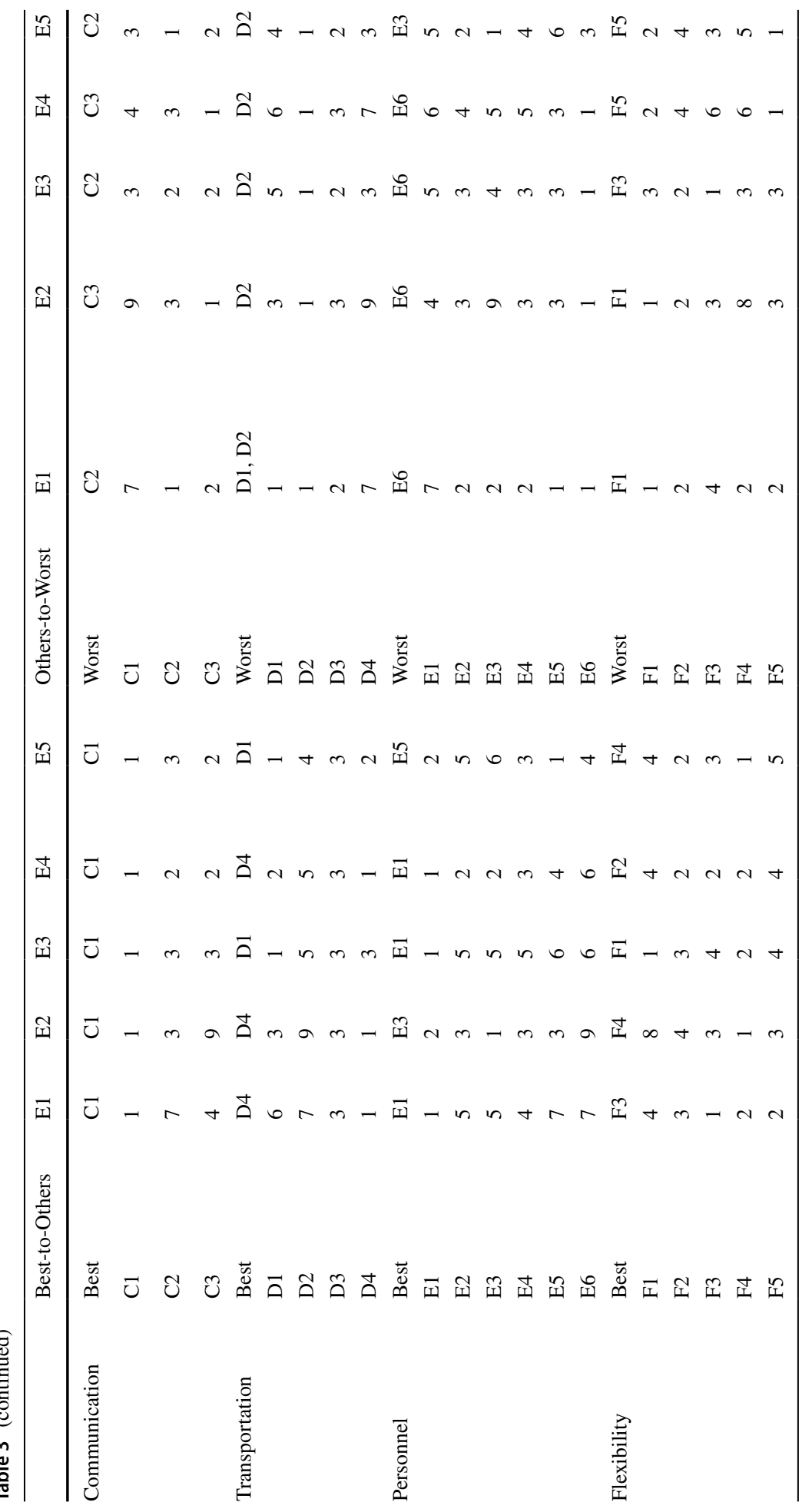


Table 4 Main criterion weights obtained with BBWM

\begin{tabular}{lll}
\hline Main Criterion & Weight & Ranking \\
\hline A & 0.122 & 4 \\
B & 0.254 & 2 \\
C & 0.120 & 5 \\
D & 0.140 & 3 \\
E & 0.256 & 1 \\
F & 0.106 & 6 \\
\hline
\end{tabular}

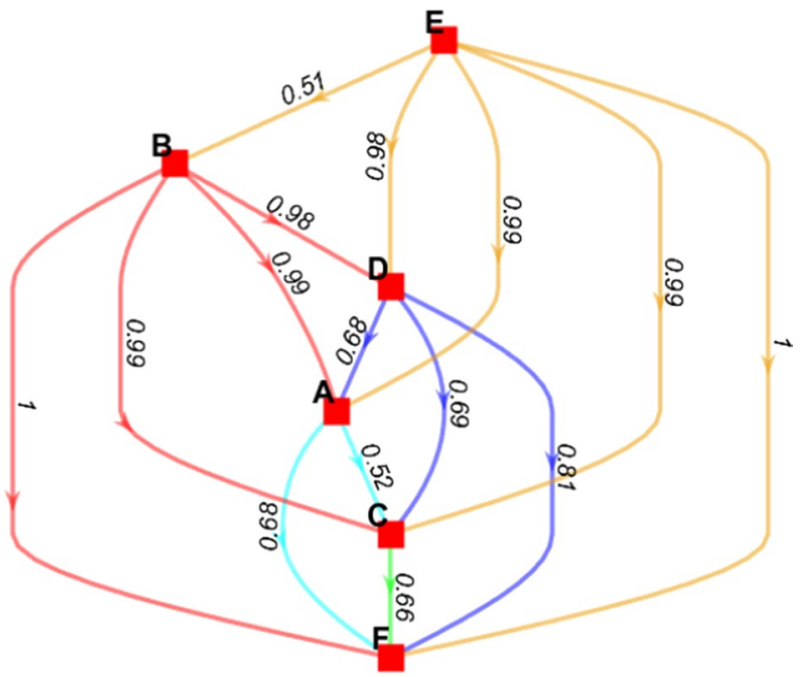

Fig. 8 Credal ranking display of main criteria

criterion was considered the cost criterion. S, R and Q values calculated for each hospital are given in Table 6 .

According to the results of VIKOR Q index values, Hospital-2 was the hospital most prepared for disasters under the evaluated criteria $(Q=0.000)$. This hospital is followed by Hospital-4(Q=0.566) and Hospital-5(Q=0.746). Other hospitals were Hospital-6 $(\mathrm{Q}=0.752)$, Hospital-3 $(\mathrm{Q}=0.779)$ and Hospital-1 $(\mathrm{Q}=1.000)$, respectively.

\subsection{Validation and comparative studies}

A comparative analysis was performed to test the robustness of the proposed method. The proposed BBWM and VIKOR integrated approach results are compared with the results of five different approaches detailed in Table 7.

As presented in Table 7, each approach consists of two stages and each stage is solved with a different tool. For example, approach 3 is a model created by integrating classical BWM and TOPSIS methods. While disaster preparedness criteria weights were determined by BWM, hospital disaster preparedness rankings were determined by the TOPSIS method. While classical BWM calculations were obtained with Lingo software, TOPSIS calculations were performed with the help of MS Excel. The results were obtained by solving each of the approaches separately. Two different solvent tools were used to determine the relative 
Table 5 Weights of sub-criteria obtained by BBWM

\begin{tabular}{|c|c|c|}
\hline Sub-criteria of hospital building & Weight & Rank \\
\hline A1 & 0.240 & 1 \\
\hline A2 & 0.139 & 3 \\
\hline A3 & 0.068 & 7 \\
\hline A4 & 0.240 & 2 \\
\hline A5 & 0.122 & 4 \\
\hline A6 & 0.099 & 5 \\
\hline A7 & 0.092 & 6 \\
\hline Sub-criteria of equipment & Weight & Rank \\
\hline B1 & 0.186 & 2 \\
\hline B2 & 0.080 & 7 \\
\hline B3 & 0.097 & 5 \\
\hline B4 & 0.206 & 1 \\
\hline B5 & 0.086 & 6 \\
\hline B6 & 0.107 & 3 \\
\hline B7 & 0.069 & 8 \\
\hline B8 & 0.106 & 4 \\
\hline B9 & 0.063 & 9 \\
\hline Sub-criteria of communication & Weight & Rank \\
\hline $\mathrm{C} 1$ & 0.590 & 1 \\
\hline $\mathrm{C} 2$ & 0.217 & 2 \\
\hline $\mathrm{C} 3$ & 0.193 & 3 \\
\hline Sub-criteria of transportation & Weight & Rank \\
\hline D1 & 0.269 & 2 \\
\hline D2 & 0.107 & 4 \\
\hline \multirow[t]{2}{*}{ D3 } & 0.203 & 3 \\
\hline & 0.421 & 1 \\
\hline Sub-criteria of personnel & Weight & Rank \\
\hline E1 & 0.288 & 1 \\
\hline E2 & 0.142 & 5 \\
\hline E3 & 0.173 & 2 \\
\hline E4 & 0.164 & 3 \\
\hline E5 & 0.145 & 4 \\
\hline E6 & 0.088 & 6 \\
\hline Sub-criteria of flexibility & Weight & Rank \\
\hline $\mathrm{F} 1$ & 0.129 & 5 \\
\hline $\mathrm{F} 2$ & 0.191 & 3 \\
\hline F3 & 0.216 & 2 \\
\hline F4 & 0.318 & 1 \\
\hline F5 & 0.146 & 4 \\
\hline
\end{tabular}




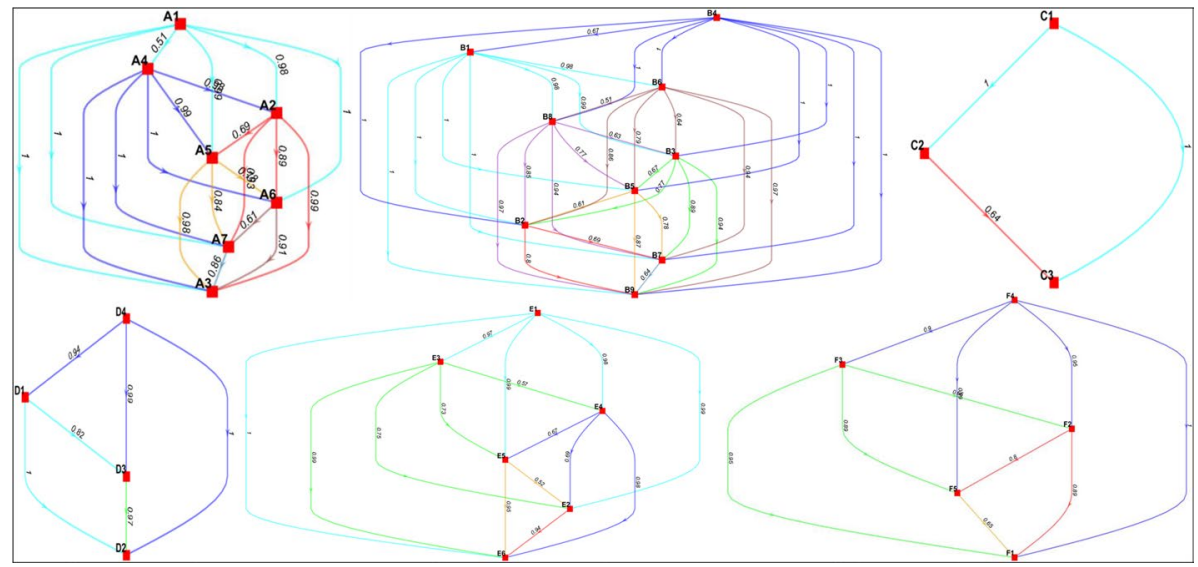

Fig. 9 Credal rank display of sub-criteria

Table 6 Calculated S, R and Q values of hospitals

\begin{tabular}{llll}
\hline & S Values & R Values & Q Values \\
\hline Hospital-1 & 0.773 & 0.074 & 1.000 \\
Hospital-2 & 0.168 & 0.059 & 0.000 \\
Hospital-3 & 0.573 & 0.072 & 0.779 \\
Hospital-4 & 0.381 & 0.071 & 0.566 \\
Hospital-5 & 0.530 & 0.072 & 0.744 \\
Hospital-6 & 0.540 & 0.072 & 0.753 \\
\hline
\end{tabular}

Table 7 Alternative approaches and solution tools

\begin{tabular}{lllll}
\hline$\#$ & \multicolumn{2}{l}{ Approach tested } & \\
\cline { 2 - 5 } & $\begin{array}{l}\text { Hospital disaster prepared- } \\
\text { ness criteria weighting }\end{array}$ & Solution tool & Hospital ranking & Solution tool \\
\hline Proposed approach & BBWM & MATLAB & VIKOR & MS Excel \\
Alternative approach-1 & BBWM & MATLAB & TOPSIS & MS Excel \\
Alternative approach-2 & BWM & Lingo & VIKOR & MS Excel \\
Alternative approach-3 & BWM & Lingo & TOPSIS & MS Excel \\
Alternative approach-4 & BWM & Excel Solver & VIKOR & MS Excel \\
Alternative approach-5 & BWM & Excel Solver & TOPSIS & MS Excel \\
\hline
\end{tabular}

importance levels (weights) of the disaster preparedness criteria of the hospitals. One of them is Excel Solver-based solver by Rezaei (2015), and the other is Lingo commercial software that can solve Quadratic programming models. The decision-maker evaluation results given in Table 3 were entered into Lingo and Excel Solver. The results of the evaluations made by the experts for each criterion using the formulas integrated into the solvers were compared with each other. For example, in the evaluations made by Expert- 1 through 
pairwise comparisons, the comparisons made for the main criteria are: (3-2-5-5-1-4) and (2-3-1-1-5-2), respectively. Solvers process these values to produce the $(0.145-0.141)$, (0.234-0.211), (0.068-0.070), (0.081-0.085), (0.369-0.387), (0.104-0.106) results. As can be seen, the slight differences in the formulas used by the solvers are also reflected in the results obtained, but they do not cause a big change in the rankings. Here, the resulting values of each expert for that criterion group must be 1 in total. Table 8 shows the weight results of both solvers depending on the experts. In Table 9, the final results consisting of local and global weight values are provided. Local weight values are obtained by averaging the five different values measured by the solvers in the expert weight results of each criterion. For example, the arithmetic average of the main criterion A in Lingo solver is $(0.145$ $+0.046+0.234+0.171+0.092) / 5=0.137$, in Excel Solver $(0.141+0.045+0.211+0.148$ $+0.081) / 5=0.125$. Likewise, differences in values do not affect the ranking.

The resulting weight vectors were added to the TOPSIS or VIKOR model according to the approach to be followed, and the disaster preparedness of the hospitals was analyzed. Tables 10 and 11 show the final scores (Q-value for VIKOR, closeness coefficient$\mathrm{CC}$ value for TOPSIS) and rankings obtained with each method. These values, which vary between 0 and 1, represent the level of preparation of each hospital according to the relevant method. The important point here is that the value being close to 1 in the methods in which TOPSIS is used indicates that the hospital's disaster preparedness is reasonable, while this is the opposite in the methods using VIKOR. The closer the VIKOR Q value is to 0 , the higher the hospital's disaster preparedness level.

According to these results, it is seen that Hospital-2 is the most disaster-ready hospital in all models. It has the highest CC score $(0.739,0.781$ and 0.776$)$ in the models which used TOPSIS along with BWM among the remaining five hospitals. On the other side, it has the lowest $\mathrm{Q}$ value ( 0.000 for each one) in the models which used VIKOR compared to the other five hospitals. These preparedness scores imply that Hospital-2 is very well-prepared. Hospital-2 is followed by Hospital-4 according to all models. It also has a relatively good preparedness with TOPSIS CC score higher than 0.3 . In a study by Choudhury et al. (20,201), which evaluates the preparedness of Indian states against COVID19 pandemic risk, this value is considered to be below the high readiness value, but not below the value of $<0.2$, which is considered inadequate preparation. Hospital-1, Hospital-3, Hospital-5 and Hospital-6 have relatively poor preparedness. In the models where TOPSIS was applied, the CC values are below 0.2. And with the same trend, their VIKOR $\mathrm{Q}$ values are high. In Choudhury et al. $(20,201)$ 's study, five clusters are created to distinguish the preparedness levels: very good (score $>0.5)$, good $(0.4<$ score $\leq 0.5)$, average $(0.3<$ score $\leq 0.4)$; poor $(0.2<$ score $\leq 0.3)$ and very poor $($ score $\leq 0.2)$. When we think according to this clustering style, it is clear that the preparation level in most hospitals in our case study is weak. Although the rankings of hospitals other than Hospital-2 and Hospital-4 are reasonably different, the results are mostly close to each other. According to these results, hospitals that are weak in terms of preparation can continue their struggle by aiming to have a good performance value under the criteria evaluated and weighted with the BBWM model. The agility of hospitals in terms of personnel and equipment, which are determined as the most important criteria according to the BBWM results, can help them to be more prepared for disasters. The operation and procedures of hospitals with high preparedness scores can be copied by the hospitals that have less preparedness to increase agility in disasters. It is an important issue for hospitals to provide the mentioned criteria by considering all stages of disaster management. The risk that arises in a single stage may harm all disaster management efforts and cause serious losses. Therefore, it is necessary to pay attention to all the mentioned criteria for disaster preparedness and good agility. 
Table 8 Weight results of expert assessments

\begin{tabular}{|c|c|c|c|c|c|c|c|c|c|c|}
\hline \multicolumn{6}{|l|}{ Lingo solver } & \multicolumn{5}{|c|}{ BWM-Solver } \\
\hline $\begin{array}{l}\text { Criteria/ } \\
\text { Sub-criteria }\end{array}$ & E-1 & E-2 & E-3 & E-4 & E-5 & E-1 & E-2 & E-3 & E-4 & E-5 \\
\hline A & 0.145 & 0.046 & 0.234 & 0.171 & 0.092 & 0.141 & 0.045 & 0.211 & 0.148 & 0.081 \\
\hline B & 0.234 & 0.405 & 0.290 & 0.225 & 0.130 & 0.211 & 0.393 & 0.338 & 0.221 & 0.141 \\
\hline $\mathrm{C}$ & 0.068 & 0.131 & 0.159 & 0.054 & 0.130 & 0.070 & 0.135 & 0.141 & 0.053 & 0.113 \\
\hline D & 0.081 & 0.131 & 0.103 & 0.063 & 0.206 & 0.085 & 0.135 & 0.106 & 0.089 & 0.188 \\
\hline E & 0.369 & 0.189 & 0.159 & 0.370 & 0.404 & 0.387 & 0.191 & 0.141 & 0.379 & 0.439 \\
\hline $\mathrm{F}$ & 0.104 & 0.098 & 0.056 & 0.117 & 0.038 & 0.106 & 0.101 & 0.063 & 0.111 & 0.039 \\
\hline A1 & 0.196 & 0.472 & 0.431 & 0.205 & 0.178 & 0.211 & 0.428 & 0.344 & 0.209 & 0.237 \\
\hline A2 & 0.086 & 0.101 & 0.084 & 0.163 & 0.156 & 0.092 & 0.115 & 0.164 & 0.139 & 0.147 \\
\hline A3 & 0.049 & 0.049 & 0.151 & 0.042 & 0.023 & 0.048 & 0.044 & 0.098 & 0.041 & 0.026 \\
\hline A4 & 0.461 & 0.176 & 0.151 & 0.344 & 0.161 & 0.441 & 0.207 & 0.123 & 0.353 & 0.147 \\
\hline A5 & 0.082 & 0.083 & 0.060 & 0.120 & 0.161 & 0.077 & 0.092 & 0.098 & 0.105 & 0.147 \\
\hline A6 & 0.063 & 0.064 & 0.070 & 0.048 & 0.161 & 0.066 & 0.057 & 0.123 & 0.070 & 0.147 \\
\hline A7 & 0.063 & 0.054 & 0.053 & 0.078 & 0.161 & 0.066 & 0.057 & 0.049 & 0.084 & 0.147 \\
\hline B1 & 0.210 & 0.139 & 0.225 & 0.238 & 0.169 & 0.194 & 0.139 & 0.244 & 0.315 & 0.156 \\
\hline B2 & 0.039 & 0.096 & 0.153 & 0.022 & 0.119 & 0.040 & 0.098 & 0.152 & 0.027 & 0.117 \\
\hline B3 & 0.048 & 0.096 & 0.132 & 0.076 & 0.119 & 0.048 & 0.098 & 0.102 & 0.077 & 0.117 \\
\hline B4 & 0.367 & 0.298 & 0.132 & 0.216 & 0.145 & 0.372 & 0.287 & 0.102 & 0.192 & 0.233 \\
\hline B5 & 0.053 & 0.096 & 0.083 & 0.046 & 0.093 & 0.055 & 0.098 & 0.102 & 0.055 & 0.117 \\
\hline B6 & 0.065 & 0.096 & 0.118 & 0.112 & 0.145 & 0.065 & 0.098 & 0.076 & 0.096 & 0.078 \\
\hline B7 & 0.092 & 0.034 & 0.061 & 0.058 & 0.066 & 0.094 & 0.033 & 0.102 & 0.064 & 0.047 \\
\hline B8 & 0.074 & 0.072 & 0.061 & 0.194 & 0.119 & 0.077 & 0.074 & 0.076 & 0.128 & 0.117 \\
\hline B9 & 0.053 & 0.072 & 0.036 & 0.039 & 0.026 & 0.055 & 0.074 & 0.046 & 0.048 & 0.019 \\
\hline $\mathrm{C} 1$ & 0.715 & 0.692 & 0.592 & 0.535 & 0.461 & 0.708 & 0.692 & 0.600 & 0.542 & 0.500 \\
\hline $\mathrm{C} 2$ & 0.100 & 0.231 & 0.242 & 0.167 & 0.373 & 0.083 & 0.231 & 0.233 & 0.167 & 0.333 \\
\hline $\mathrm{C} 3$ & 0.185 & 0.077 & 0.167 & 0.299 & 0.167 & 0.208 & 0.077 & 0.167 & 0.292 & 0.167 \\
\hline D1 & 0.104 & 0.187 & 0.533 & 0.451 & 0.271 & 0.092 & 0.188 & 0.518 & 0.466 & 0.287 \\
\hline D2 & 0.090 & 0.063 & 0.095 & 0.104 & 0.061 & 0.092 & 0.063 & 0.089 & 0.103 & 0.067 \\
\hline D3 & 0.194 & 0.187 & 0.147 & 0.171 & 0.271 & 0.215 & 0.188 & 0.196 & 0.172 & 0.191 \\
\hline D4 & 0.613 & 0.563 & 0.225 & 0.274 & 0.397 & 0.600 & 0.563 & 0.196 & 0.259 & 0.455 \\
\hline E1 & 0.518 & 0.183 & 0.514 & 0.225 & 0.348 & 0.507 & 0.185 & 0.468 & 0.221 & 0.325 \\
\hline E2 & 0.112 & 0.127 & 0.088 & 0.063 & 0.139 & 0.107 & 0.130 & 0.122 & 0.089 & 0.200 \\
\hline E3 & 0.112 & 0.392 & 0.155 & 0.054 & 0.187 & 0.107 & 0.380 & 0.122 & 0.053 & 0.200 \\
\hline E4 & 0.118 & 0.127 & 0.088 & 0.171 & 0.187 & 0.134 & 0.130 & 0.122 & 0.148 & 0.133 \\
\hline E5 & 0.070 & 0.127 & 0.088 & 0.370 & 0.090 & 0.068 & 0.130 & 0.101 & 0.379 & 0.100 \\
\hline E6 & 0.070 & 0.044 & 0.067 & 0.117 & 0.049 & 0.077 & 0.043 & 0.066 & 0.111 & 0.042 \\
\hline $\mathrm{F} 1$ & 0.093 & 0.059 & 0.382 & 0.113 & 0.059 & 0.085 & 0.059 & 0.375 & 0.118 & 0.118 \\
\hline $\mathrm{F} 2$ & 0.154 & 0.117 & 0.101 & 0.278 & 0.294 & 0.136 & 0.124 & 0.167 & 0.237 & 0.353 \\
\hline F3 & 0.407 & 0.170 & 0.074 & 0.161 & 0.294 & 0.373 & 0.166 & 0.083 & 0.158 & 0.235 \\
\hline F4 & 0.173 & 0.484 & 0.308 & 0.381 & 0.294 & 0.203 & 0.485 & 0.250 & 0.416 & 0.235 \\
\hline F5 & 0.173 & 0.170 & 0.135 & 0.068 & 0.059 & 0.203 & 0.166 & 0.125 & 0.072 & 0.059 \\
\hline
\end{tabular}


Table 9 Final results (local and global weight values)

\begin{tabular}{|c|c|c|c|c|c|}
\hline \multicolumn{3}{|l|}{ Lingo solver } & \multicolumn{3}{|l|}{ BWM-solver } \\
\hline $\begin{array}{l}\text { Criteria/sub- } \\
\text { criteria }\end{array}$ & Local weight & Global weight & $\begin{array}{l}\text { Criteria/sub- } \\
\text { criteria }\end{array}$ & Local weight & Global weight \\
\hline A & 0.137 & & A & 0.125 & \\
\hline A1 & 0.297 & 0.041 & A1 & 0.286 & 0.039 \\
\hline A2 & 0.118 & 0.016 & $\mathrm{~A} 2$ & 0.131 & 0.018 \\
\hline A3 & 0.063 & 0.009 & A3 & 0.051 & 0.007 \\
\hline A4 & 0.259 & 0.036 & A4 & 0.254 & 0.035 \\
\hline A5 & 0.101 & 0.014 & A5 & 0.104 & 0.014 \\
\hline A6 & 0.081 & 0.011 & A6 & 0.093 & 0.013 \\
\hline A7 & 0.082 & 0.011 & A7 & 0.081 & 0.011 \\
\hline B & 0.257 & & $\mathrm{~B}$ & 0.261 & \\
\hline B1 & 0.196 & 0.050 & B1 & 0.209 & 0.054 \\
\hline B2 & 0.086 & 0.022 & B2 & 0.087 & 0.022 \\
\hline B3 & 0.094 & 0.024 & B3 & 0.088 & 0.023 \\
\hline B4 & 0.232 & 0.059 & B4 & 0.237 & 0.061 \\
\hline B5 & 0.074 & 0.019 & B5 & 0.085 & 0.022 \\
\hline B6 & 0.107 & 0.028 & B6 & 0.083 & 0.021 \\
\hline B7 & 0.062 & 0.016 & B7 & 0.068 & 0.017 \\
\hline B8 & 0.104 & 0.027 & B8 & 0.094 & 0.024 \\
\hline B9 & 0.045 & 0.012 & B9 & 0.048 & 0.012 \\
\hline $\mathrm{C}$ & 0.108 & & $\mathrm{C}$ & 0.102 & \\
\hline $\mathrm{C} 1$ & 0.599 & 0.065 & $\mathrm{C} 1$ & 0.608 & 0.066 \\
\hline $\mathrm{C} 2$ & 0.222 & 0.024 & $\mathrm{C} 2$ & 0.209 & 0.023 \\
\hline C3 & 0.179 & 0.019 & $\mathrm{C} 3$ & 0.182 & 0.020 \\
\hline D & 0.117 & & $\mathrm{D}$ & 0.120 & \\
\hline D1 & 0.310 & 0.036 & D1 & 0.310 & 0.036 \\
\hline D2 & 0.082 & 0.010 & D2 & 0.083 & 0.010 \\
\hline D3 & 0.194 & 0.023 & D3 & 0.193 & 0.022 \\
\hline D4 & 0.414 & 0.048 & D4 & 0.415 & 0.048 \\
\hline E & 0.298 & & $\mathrm{E}$ & 0.307 & \\
\hline E1 & 0.357 & 0.107 & E1 & 0.341 & 0.102 \\
\hline E2 & 0.106 & 0.032 & E2 & 0.130 & 0.039 \\
\hline E3 & 0.180 & 0.054 & E3 & 0.172 & 0.051 \\
\hline E4 & 0.138 & 0.041 & E4 & 0.133 & 0.040 \\
\hline E5 & 0.149 & 0.044 & E5 & 0.156 & 0.046 \\
\hline E6 & 0.069 & 0.021 & E6 & 0.068 & 0.020 \\
\hline $\mathrm{F}$ & 0.083 & & $\mathrm{~F}$ & 0.084 & \\
\hline $\mathrm{F} 1$ & 0.141 & 0.012 & F1 & 0.151 & 0.012 \\
\hline $\mathrm{F} 2$ & 0.189 & 0.016 & F2 & 0.203 & 0.017 \\
\hline F3 & 0.221 & 0.018 & F3 & 0.203 & 0.017 \\
\hline F4 & 0.328 & 0.027 & F4 & 0.318 & 0.026 \\
\hline F5 & 0.121 & 0.010 & F5 & 0.125 & 0.010 \\
\hline
\end{tabular}


Table 10 Hospitals' final scores

\begin{tabular}{lllllll}
\hline Method & \multicolumn{6}{l}{ Q value/CC value } \\
\cline { 2 - 7 } & Hospital -1 & Hospital -2 & Hospital -3 & Hospital -4 & Hospital -5 & Hospital -6 \\
\hline BBWM-VIKOR & 1.000 & 0.000 & 0.779 & 0.566 & 0.744 & 0.753 \\
BWM-VIKOR* $^{*}$ & 1.000 & 0.000 & 0.835 & 0.663 & 0.803 & 0.813 \\
BWM-VIKOR ** $^{*}$ & 1.000 & 0.000 & 0.830 & 0.659 & 0.803 & 0.814 \\
BBWM-TOPSIS $^{0.228}$ & 0.739 & 0.206 & 0.350 & 0.238 & 0.201 \\
BWM-TOPSIS* & 0.219 & 0.781 & 0.183 & 0.307 & 0.208 & 0.174 \\
BWM-TOPSIS** & 0.226 & 0.776 & 0.184 & 0.311 & 0.213 & 0.177 \\
\hline
\end{tabular}

*Classical BWM weight vector calculated with Lingo

**The classical BWM weight vector was calculated with Excel Solver

Table 11 Ranking of hospitals

\begin{tabular}{lllllll}
\hline Method & \multicolumn{2}{l}{ Ranking } & & & \\
\cline { 2 - 7 } & Hospital -1 & Hospital -2 & Hospital -3 & Hospital -4 & Hospital -5 & Hospital -6 \\
\hline BBWM-VIKOR & 6 & 1 & 5 & 2 & 3 & 4 \\
BWM-VIKOR * & 6 & 1 & 5 & 2 & 3 & 4 \\
BWM-VIKOR ** & 6 & 1 & 5 & 2 & 3 & 4 \\
BBWM-TOPSIS & 4 & 1 & 5 & 2 & 3 & 6 \\
BWM-TOPSIS $*$ & 3 & 1 & 5 & 2 & 4 & 6 \\
BWM-TOPSIS $* *$ & 3 & 1 & 5 & 2 & 4 & 6 \\
\hline
\end{tabular}

*Classical BWM weight vector calculated with Lingo

**The classical BWM weight vector was calculated with Excel Solver

When the correlation analysis was performed between the final scores of each model, a correlation coefficient of over $90 \%$ was obtained in all combinations, as seen in Table 12. This result reinforces that our proposed model produces results close to other studied models and is applicable in hospital disaster preparedness assessment.

In addition to the comparison analysis mentioned above, a sensitivity analysis specific to the VIKOR method was also performed. The aim here is to observe how the final score and rankings change in the " $v$ " value variability, which expresses the maximum group utility in VIKOR. Table 13 and Fig. 10 show the change in the $\mathrm{Q}$ values obtained when $v$ changes from 0 to 1 with 0.1 intervals. The results showed that the trend of VIKOR Q values did not change at all $v$ values. The $v$ value change has not affected hospital rankings. In other words, if the $v=1.0$ or $v=0.0$ is determined, ranking is significant.

\section{Conclusion}

People can overcome their painful experiences or severe health problems, hoping that hospitals can meet their expectations when they are in extreme physical conditions, technical facilities and all their employees. In order to meet this intense expectation, a hospital 


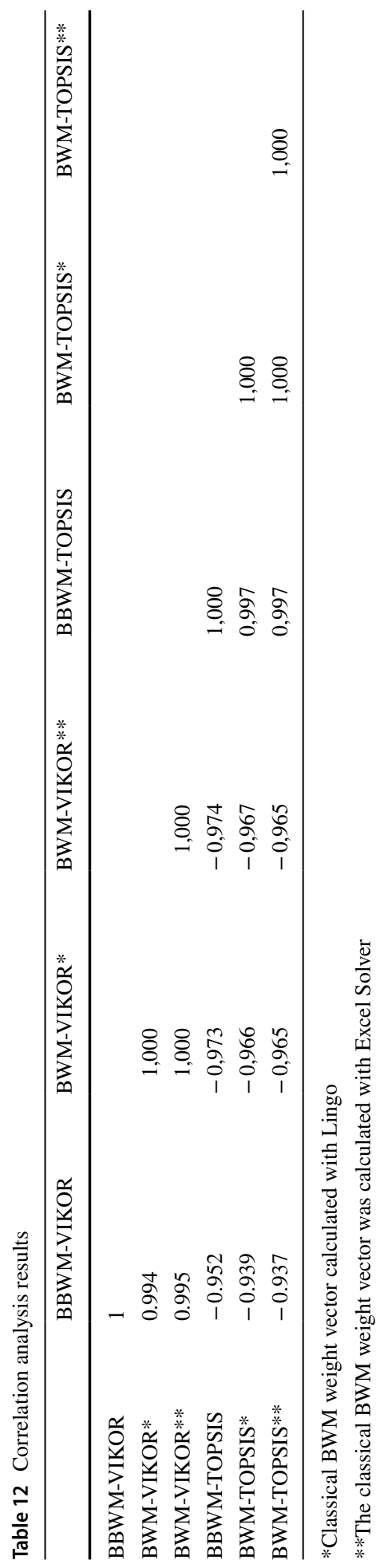


Table 13 VIKOR Q values for different $v$ values

\begin{tabular}{llllllllllllll}
\hline Hospital & \multicolumn{1}{l}{ VIKOR Q value } \\
\cline { 2 - 7 } & $v=0.1$ & $v=0.2$ & $v=0.3$ & $v=0.4$ & $v=0.5$ & $v=0.6$ & $v=0.7$ & $v=0.8$ & $v=0.9$ & $v=1.0$ \\
\hline Hospital-2 & 0.000 & 0.000 & 0.000 & 0.000 & 0.000 & 0.000 & 0.0000 & 0.000 & 0.000 & 0.000 & 0.000 \\
Hospital-4 & 0.779 & 0.736 & 0.694 & 0.651 & 0.609 & 0.566 & 0.5236 & 0.481 & 0.439 & 0.396 & 0.353 \\
Hospital-5 & 0.889 & 0.860 & 0.831 & 0.802 & 0.773 & 0.744 & 0.7144 & 0.685 & 0.656 & 0.627 & 0.598 \\
Hospital-6 & 0.889 & 0.862 & 0.835 & 0.807 & 0.780 & 0.753 & 0.7253 & 0.698 & 0.671 & 0.643 & 0.616 \\
Hospital-3 & 0.889 & 0.867 & 0.845 & 0.823 & 0.801 & 0.779 & 0.7570 & 0.735 & 0.713 & 0.691 & 0.669 \\
Hospital-1 & 1.000 & 1.000 & 1.000 & 1.000 & 1.000 & 1.000 & 1.0000 & 1.000 & 1.000 & 1.000 & 1.000 \\
\hline
\end{tabular}

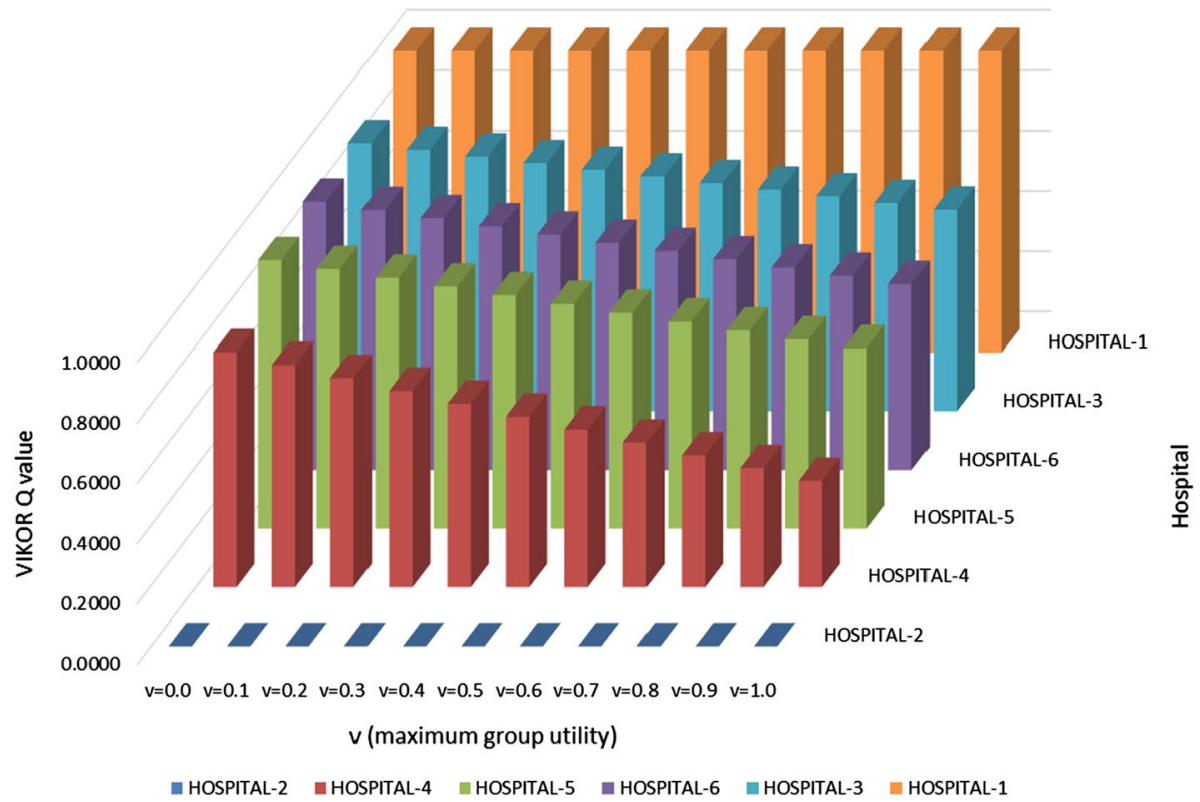

Fig. 10 Variation of VIKOR Q values for each hospital at change in $v$ value

disaster readiness planning prepared considering all possible problems can return as profit in every sense. Based on the results of this study, we aim to prevent losses.

\section{Summary of the results}

In this study, a decision model has been developed for the evaluation of disaster preparedness of hospitals. This decision model includes BBWM, VIKOR and TOPSIS MCDM methods. With the proposed approach, six main criteria and 34 sub-criteria related to disaster preparedness of hospitals were evaluated. The criteria and sub-criteria evaluated by the experts in pairwise comparison manner were weighted with BBWM. The weight values obtained and the data obtained from the hospitals were combined to provide input for 
VIKOR and TOPSIS. In addition, comparison and sensitivity analysis studies were carried out using weight vectors obtained with different tools. According to the results by BBWM, the "Personnel" criterion was determined as the most important criterion with an importance value of $26 \%$. This criterion is followed by "Equipment" with 25\%, "Transportation" with 14\%, "Hospital Building" and "Communication" with $12 \%$, and "Flexibility" with $11 \%$. As a result of the VIKOR application, Hospital-2 is the most prepared hospital for disasters. The VIKOR $Q$ value of this hospital was obtained as 0.000 . This hospital is followed by Hospital-4 $(\mathrm{Q}=0.5661)$ and Hospital-5 $(\mathrm{Q}=0.7464)$. The fourth, fifth and last hospitals were Hospital-6, Hospital-3 and Hospital-1, respectively. According to the comparison analysis results, Hospital-2 is placed as the most disaster-ready hospital in all six different approaches. Hospital-2 is followed by Hospital-4 according to all approaches. Although the hospital rankings obtained according to some approaches have minimal differences, it has been confirmed by the correlation analysis that the majority of the results are close to each other. The correlation between the final scores of the models is over $90 \%$ in all combinations. In sensitivity analysis, the change in $\mathrm{Q}$ value was analyzed by changing the maximum group benefit parameter in the VIKOR method. It was observed that the trend of the $\mathrm{Q}$ value did not change according to all the variations tried.

\subsection{Methodological and practical contributions}

Due to the limited MCDM-based approaches to the disaster preparedness assessment of hospitals, the methodology proposed in this study contributes to the literature in terms of both theory and practice. We can summarize these contributions as follows:

- BBWM is integrated with both TOPSIS and VIKOR methods and applied to a problem within the scope of disaster management for the first time. With the use of BBWM, the opinions of the expert group were combined without loss of information and the criterion and sub-criteria weights were determined with a lesser pairwise comparison from a probabilistic view. With the "Credal Ranking," which is the contribution of BBWM to the literature, the interpretation of the hierarchy between each criterion has been performed more precisely.

- In the process of evaluating the disaster preparedness criteria and sub-criteria, a wellequipped expert group directly related to the subject has been worked with.

- Pearson correlation analysis was used to analyze the relationship between the results produced by alternative approaches that tested the applicability and robustness of the method with a detailed comparison study.

- This study has theoretical contributions as well as practical contributions. Although the model predicts a ranking among a limited number of hospitals, it contributes to the literature because it is an adaptable model on a regional and national scale. The model proposed here can be applied by central policymakers for all hospitals across the country and can be evaluated as a guiding tool in preparing for disasters.

\subsection{Limitations}

Despite the contributions highlighted above, the study has some limitations. The first of these is the evaluation of a limited number of hospitals within the scope of the study and the general difficulties in data collection. The second is that a coefficient of expertise is not used for each expert group member evaluated during the BBWM implementation phase. 
The third limitation is that various fuzzy logic extensions are not included in the study to reflect better the uncertainty and subjectivity inherent in expert assessments of real-world problems. In this context, a new MCDM model enriched with these extensions can be developed for future studies.

\subsection{Future research agenda}

In the model, different weight matrices were obtained with the help of two different tools in determining the criteria and sub-criteria weights. The expert evaluations used in obtaining them are the same. What is different is the tool with which the solution is made. Therefore, different MCDM methods such as classical BWM, revised AHP, DEMATEL, ANP can be used to determine criterion weights in future studies. In addition, D-ANP, a combined method of DEMATEL-ANP, in which the interaction between the criteria is taken into account, can also be used. The criteria set used in the study can be revised considering various dynamic situations. The sensitivity of hospital staff to disasters and disaster culture can be included in the criteria set in this context. In addition, preparedness criteria specific to epidemic disasters, which the world has been struggling with recently, can be developed and added to the criteria pool. Considering the disaster classification of EM-DAT, different models can be suggested to prepare hospitals for each type of disaster.

\section{Declarations}

Conflict of interest The authors declare that they do not have conflict of interest.

\section{References}

Adini B, Goldberg A, Laor D, Cohen R, Zadok R, Bar-Dayan Y (2006) Assessing levels of hospital emergency preparedness. Prehosp Disaster Med 21(6):451-457

Al Thobaity A, Alamri S, Plummer V, Williams B (2019) Exploring the necessary disaster plan components in Saudi Arabian hospitals. Int J Disaster Risk Reduction 41:101316

Alruwaili A, Islam S, Usher K (2019) Disaster preparedness in hospitals in the Middle East: an integrative literature review. Disaster Med Publ Health Preparedness 13(4):806-816

Choudhury S, Majumdar A, Saha AK, Majumdar P (2021) Evaluating the preparedness of Indian states against COVID-19 pandemic risk: a fuzzy multi-criteria decision-making approach. Risk Anal. https:// doi.org/10.1111/risa.13808

Dong JY, Yuan FF, Wan SP (2017) Extended VIKOR method for multiple criteria decision-making with linguistic hesitant fuzzy information. Comput Indus Eng 112:305-319

EM-DAT (2021) Emergency database. https://www.emdat.be/emdat_db. Disasters in Turkey in the last 20 years. 30 Jan 2021

Gao H, Ran L, Wei G, Wei C, Wu J (2020) VIKOR method for MAGDM based on q-rung interval-valued orthopair fuzzy information and its application to supplier selection of medical consumption products. Int J Environ Res Publ Health 17(2):525

Gul M, Guneri AF (2015) Are emergency departments in 1stanbul ready for the earthquakes? Past experience and suggestions for future preparedness from employees' viewpoint and the literature. Homel Secur Emerg Manag 12(4):967-983

Gul M, Celik E, Aydin N, Gumus AT, Guneri AF (2016) A state of the art literature review of VIKOR and its fuzzy extensions on applications. Appl Soft Comput 46:60-89

Gul M, Yucesan M (2021) Hospital preparedness assessment against COVID-19 pandemic: a case study in Turkish tertiary healthcare services. Math Probl Eng 2021:18. https://doi.org/10.1155/2021/2931219

Hafezalkotob A, Hafezalkotob A (2017) A novel approach for combination of individual and group decisions based on fuzzy best-worst method. Appl Soft Comput 59:316-325 
Hosseini SM, Bahadori M, Raadabadi M, Ravangard R (2019) Ranking hospitals based on the disasters preparedness using the TOPSIS technique in Western Iran. Hosp Top 97(1):23-31

Hsu W-CJ, Lo H-W, Yang C-C (2021) The formulation of epidemic prevention work of covid-19 for colleges and universities: priorities and recommendations. Sustainability 13(4):1-19

Jahan A, Mustapha F, Ismail MY, Sapuan SM, Bahraminasab M (2011) A comprehensive VIKOR method for material selection. Mater Des 32(3):1215-1221

Kaji AH, Koenig KL, Lewis RJ (2007) Current hospital disaster preparedness. J Am Med as 298(18):2188-2190

Marzaleh MA, Rezaee R, Rezaianzadeh A, Rakhshan M, Haddadi G, Peyravi M (2019) Developing a model for hospitals' emergency department preparedness in radiation and nuclear incidents and nuclear terrorism in Iran. Bull Emerg Trauma 7(3):300-306

Mohammadi M, Rezaei J (2020a) Bayesian best-worst method: a probabilistic group decision making model. Omega 96:102075

Mohammadi M, Rezaei J (2020b) Evaluating and comparing ontology alignment systems an MCDM approach. J Web Semant 64:100592

Moheimani A, Sheikh R, Hosseini SMH, Sana SS (2021a) Assessing the preparedness of hospitals facing disasters using the rough set theory: guidelines for more preparedness to cope with the COVID19. Int J Syst Sci Oper Logist 8:1-16

Moheimani A, Sheikh R, Hosseini SMH, Sana SS (2021b) Assessing the agility of hospitals in disaster management: application of interval type-2 fuzzy Flowsort inference system. Soft Comput 25(5):3955-3974

Mulyasari F, Inoue S, Prashar S, Isayama K, Basu M, Srivastava N, Shaw R (2013) Disaster preparedness: looking through the lens of hospitals in Japan. Int J Disaster Risk Sci 4(2):89-100

Munasinghe NL, Matsui K (2019) Examining disaster preparedness at Matara District General Hospital in Sri Lanka. Int J Disaster Risk Reduct 40:101154

Mou Q, Xu Z, Liao H (2016) An intuitionistic fuzzy multiplicative best-worst method for multi-criteria group decision making. Inf Sci 374:224-239

Naser WN, Ingrassia PL, Aladhrae S, Abdulraheem WA (2018) A study of hospital disaster preparedness in South Yemen. Prehosp Disaster Med 33(2):133-138

Nekoie-Moghadam M, Kurland L, Moosazadeh M, Ingrassia PL, Della Corte F, Djalali A (2016) Tools and checklists used for the evaluation of hospital disaster preparedness: a systematic review. Disaster Med Publ Health Preparedness 10(5):781-788

Olivieri C, Ingrassia PL, Della Corte F, Carenzo L, Sapori J-M, Gabilly L, Segond F, Grieger F, ArnodPrin P, Larrucea X, Violi C, Lopez C, Djalali A (2017) Hospital preparedness and response in CBRN emergencies: TIER assessment tool. Eur J Emerg Med 24(5):366-370

Opricovic S (1998) Multicriteria optimization of civil engineering systems. Fac Civ Eng Belgrade 2(1):5-21

Opricovic S, Tzeng GH (2004) Compromise solution by MCDM methods: a comparative analysis of VIKOR and TOPSIS. Eur J Oper Res 156(2):445-455

Ortiz Barrios MA, Gul M, López-Meza P, Yucesan M, Navarro-Jiménez E (2020) Evaluation of hospital disaster preparedness by an FAHP-FDEMATEL-TOPSIS hybrid approach: the case of Turkish hospitals. Int J Disaster Risk Reduc 49:101748

Ortiz-Barrios MA, Herrera-Fontalvo Z, Rúa-Muñoz J, Ojeda-Gutiérrez S (2017) An integrated approach to evaluate the risk of adverse events in hospital sector. Manag Decis 56(10):2187-2224

Rafieyan E, Khorsand R, Ramezanpour M (2020) An adaptive scheduling approach based on integrated best-worst and VIKOR for cloud computing. Comput Indus Eng 140:106272

Rezaei J (2015) Best-worst multi-criteria decision-making Method. Omega (united Kingdom) 53:49-57

Rezaei F, Mohebbi-Dehnavi Z (2019) Evaluation of the readiness of hospitals affiliated to Isfahan University of Medical Sciences in unexpected events in 2017. J Educ Health Promot 8:7.https://doi.org/ 10.4103/jehp.jehp_83_18

Saeid M, Khankeh H, Habibisoola A, Mohammadali M, Hamidkolg G, Dadkhah B (2019) Investigating hospital preparedness in Ardabil Province against unexpected accidents. Health Emerg Disasters 4(3):127-134

Samsuddin NM, Takim R, Nawawi AH, Alwee SNAS (2018) Disaster preparedness attributes and hospital's resilience in Malaysia. Procedia Eng 212:371-378

Shabanikiya H, Jafari M, Gorgi HA, Seyedin H, Rahimi A (2019) Developing a practical toolkit for evaluating hospital preparedness for surge capacity in disasters. Int J Disaster Risk Reduc 34:423-428

Tabatabaei SAN, Abbasi S (2016) Risk assessment in social security hospitals of Isfahan Province in case of disasters based on the hospital safety index. Int J Health Syst Disaster Manag 4(3):82 
Top M, Gider Ö, Tas Y (2010) An investigation of hospital disaster preparedness in Turkey. J Homel Secur Emerg Manag 7(1):69

UN (2009) United Nations international strategy for disaster risk reduction (UNISDR), "Disaster risk reduction terminology" https://www.unisdr.org/2009/campaign/pdf/wdrc-2008-2009-information-kit.pdf

URL-1 (2021) https://github.com/Majeed7/BayesianBWM. Application steps of Bayesian BWM. 02 Feb 2021

Verheul ML, Dückers ML (2020) Defining and operationalizing disaster preparedness in hospitals: a systematic literature review. Prehospital Disaster Med 35(1):61-68

WHO (2018) İklim değişikliği ve sağlık. https://apps.who.int/iris/bitstream/handle/10665/276405/97892 41514972-eng.pdf?ua=1

WHO/PWHO (1996) Disaster reduction in healthcare facilities. http://helid.digicollection.org/en/p/print able.html

WHO/PWHO (2003) Protecting new healthcare facilities from natural disasters: promoting disaster reduction. https://www.preventionweb.net/files/629_10343.pdf

WHO/PWHO (2005). Safe hospital: collective responsibility - a global measure of disaster reduction. http:// www1.paho.org/english/dd/ped/SafeHospitalsBooklet.pdf

Yang J-J, Chuang Y-C, Lo H-W, Lee T-I (2020) A two-stage MCDM model for exploring the influential relationships of sustainable sports tourism criteria in Taichung City. Int J Environ Res Public Health 17(7):2319

Yi P, George SK, Paul JA, Lin L (2010) Hospital capacity planning for disaster emergency management. Socioecon Plann Sci 44(3):151-160

Zhong S, Clark M, Hou X, Zang YL, Fitzgerald G (2014) Development of hospital disaster resilience: conceptual framework and potential measurement. Emerg Med J 31:930-938

Publisher's Note Springer Nature remains neutral with regard to jurisdictional claims in published maps and institutional affiliations.

\section{Authors and Affiliations}

\section{Halit Serdar Saner ${ }^{1} \cdot$ Melih Yucesan $^{2} \cdot$ Muhammet Gul $^{2}$}

Halit Serdar Saner

hserdarsaner@munzur.edu.tr

Melih Yucesan

melihyucesan@munzur.edu.tr

1 Department of Engineering Management, Munzur University, 62000 Tunceli, Turkey

2 Department of Emergency Aid and Disaster Management, Munzur University, 62000 Tunceli, Turkey 